\title{
REORDENAR LA CIUDAD. POLICÍA URBANA, ORDEN PÚBLICO Y CONTROL SOCIAL EN MADRID DEL SEXENIO DEMOCRÁTICO ${ }^{1}$
}

\author{
Reordering the City. Urban Police, Public Order and Social \\ Control in Madrid during the Democratic Sexennial
}

\author{
Santiago de Miguel Salanova ${ }^{2}$ \\ sdmiguel@ghis.ucm.es \\ Universidad Complutense de Madrid \\ Fecha de recepción: 28/04/2020 \\ Fecha de aceptación: 27/06/2020
}

Resumen: Pese a la riqueza que evidencia en sus análisis locales, la producción historiográfica sobre el Sexenio Democrático presenta vacíos significativos en lo que respecta a la evolución de Madrid. El presente artículo buscará cubrir algunos de ellos centrándose en el estudio de las dinámicas que a lo largo de ese período advirtieron los poderes locales de la ciudad, sometidos a una experiencia democratizadora. A partir de la consulta de la documentación de policía urbana del Ayuntamiento de

${ }^{1}$ El presente trabajo ha sido posible gracias a la financiación obtenida en los siguientes proyectos. Proyecto de investigación "La sociedad urbana en España, 1860-1983. De los ensanches a las áreas metropolitanas, cambio social y modernización», PGC2018-096461B-C41, "Proyectos I+D de Generación de Conocimiento». Programa Estatal de Generación de Conocimiento y Fortalecimiento Científico y Tecnológico del Sistema de I+D+i financiado por Ministerio de Ciencia, Innovación y Universidades / Unión Europea. Fondo Europeo de Desarrollo Regional. MICINN/FEDER (Investigador principal: Luis Enrique Otero Carvajal). Proyecto «Gobernar la ciudad. La transición urbana como objeto político de los poderes locales en la España Contemporánea (1900-1936)». Ayudas para la realización de proyectos de I+D para jóvenes doctores. Convocatoria 2019, entidades financiadoras: Universidad Complutense de Madrid y Comunidad de Madrid. Referencia: PR65/19-22409 (Investigador principal: Santiago de Miguel Salanova).

2 Becario postdoctoral del Programa de Atracción de Talento de la Comunidad de Madrid. 2017. Modalidad 2 (jóvenes doctores). Ficha: 2017-T2/HUM-5216. 
Madrid, se abordarán las políticas de intervención de un gobierno municipal renovado en sus idearios con relación al cambio de escala que había reflejado la urbe en las últimas décadas del período monárquico. De manera específica, se estudiarán las iniciativas concernientes a la implementación de unos mecanismos de «buen gobierno» en la ciudad, los cuales, en realidad, encubrían la pretensión de reconfigurar el espacio urbano para hacerlo legible y transparente en cuanto concernía a sus usos y prácticas sociales cotidianas.

Palabras clave: Madrid; Sexenio Democrático; espacio urbano; orden público; control social.

Abstract: Despite the plethora of its available studies at local level, the historiographic production on the Democratic Sexennial presents significant gaps in terms of Madrid's evolution. This article will seek to cover some of those gaps by focusing on the study of the dynamics that the local authorities of that city, subject to a democratising experience, developed throughout that period. Based on the research of the urban police documentation of Madrid City Council between 1868 and 1873, we will delve into the intervention policies of a municipal government renewed in its ideals, in relation to the change of scale that Madrid had reflected during the last decades of the monarchical era. More specifically, we will study the local initiatives concerning the implementation of good governance mechanisms in the city. Mechanisms that, in fact, covered up the attempt to reconfigure the urban space, in order to make it more legible and transparent with regard to its uses and social practices on a daily basis.

Keywords: Madrid; Democratic Sexennial; urban space; public order; social control.

SUMARIO: 1. Introducción. 2. Gobernar lo cotidiano tras la Revolución. El pretendido tránsito hacia la legibilidad del espacio público y la aplicación de nuevas gramáticas en la policía urbana. 3 . El despliegue de las prácticas de profilaxis y control social en la ciudad en el Sexenio Democrático. 4. Conclusiones. 5. Referencias bibliográficas.

\section{INTRODUCCIÓN}

En un reciente balance historiográfico sobre el Sexenio Democrático, publicado en el marco del segundo fulgor de la memoria de la Revolución de 1868 motivado por su 150 aniversario ${ }^{3}$, Rafael Serrano, uno de los principales especialistas en ese período ${ }^{4}$, consignaba como una de sus líneas de investigación más acabadas la relacionada con el análisis de lo acontecido durante esos años a nivel local ${ }^{5}$. El historiador resaltaba la trascendencia de la obra de Eloy Arias sobre Sevilla (Arias, 2009a, 2009b y 2010), describiéndola como un «punto de no retorno» para la mencionada temática. Una temática que, a su juicio, habría agotado ya un ciclo, sin que ello fuera óbice para "seguir explorando en esa dirección», especialmente donde seguían presentándose «huecos importantes». De entre todos esos huecos, era el

${ }^{3}$ Destáquese en ese contexto el dossier editado por Rafael Villena bajo el título «Revisitar la Gloriosa», en: Ayer, 112, 2018, pp. 13-184.

4 Serrano, 1992 y 2002.

${ }^{5}$ Serrano, 2018, pp. 15-44. Su lectura debe realizarse en paralelo con la revisión bibliográfica que el autor ofreció en el monográfico de Ayer dedicado al Sexenio, en: Serrano, 2001, pp. 11-32. 
relacionado con Madrid el que el autor encontraba como «más clamoroso» (Serrano, 2018, p. 18).

En efecto, Madrid no cuenta con un estudio monográfico que detalle la evolución de sus dinámicas políticas, sociales y económicas durante la Gloriosa. Es cierto que no faltan incursiones historiográficas que evidencian la manera en que las principales características de esa etapa a nivel nacional se proyectaron en la capital española. Incursiones que, en líneas generales, han incidido en los condicionantes de la ciudad antes del estallido revolucionario (crisis económica y de subsistencias, paralización de la coyuntura de pleno empleo entre 1859 y 1864), en la conflictividad social del Sexenio (sostenida por la incapacidad del Ayuntamiento para reactivar el mercado laboral) y en el asociacionismo burgués y obrero del período (Flaquer, 1977; Bahamonde y Toro, 1978a, pp. 55-90 y Bahamonde, 1980, pp. 143175). No han faltado tampoco visiones generales sobre procesos fundamentales de esos años, como el escenario de experiencia electoral abierto tras la aprobación del sufragio universal masculino (Bahamonde, 1976; Fernández García, 2003; PaIlol, 2013); las líneas de estructuración tejidas por el republicanismo (Pérez Roldán, 2001) y las propuestas que desde la administración local se comprometieron con la transformación urbanística del Madrid isabelino, lideradas por los planes de Ángel Fernández de los Ríos para crear una ciudad "polifocal» (Espadas, 1981, p. 11) ${ }^{6}$ y por el impulso definitivo que adquirió la idea de una nueva urbe, extendida más allá de la cerca fiscal que rodeaba el casco antiguo desde los tiempos de Felipe IV y plasmada en el proyecto de Ensanche (Pallol, 2015; Vicente, 2015 y Carballo, 2015).

Aun siendo incontestable la relevancia de esas incursiones, no es menos cierto que dibujan un panorama todavía fragmentario del Sexenio en Madrid. Quedan vacíos por cubrir que atañen a temáticas insoslayables de otros trabajos que para esa época han desplegado su atención en aspectos como las actuaciones de las Juntas Revolucionarias; los procesos de articulación del nuevo poder político; los signos de cambio y continuidad que el anterior ofreció con respecto al ciclo isabelino y la Restauración; la evolución, composición y cometidos de los Voluntarios de la Libertad; el grado de politización que se alcanzó a nivel popular y el papel que jugaron los partidos y sus bases sociales en ese proceso; y las respuestas y soluciones que se ofrecieron ante problemas cotidianos que excedían los registrados en el escenario laboral ${ }^{7}$. Asimismo, y a diferencia de lo que ocurre con Barcelona (Cañellas, 1993, pp. 18-23), no hay un balance superficial sobre lo que supuso la práctica de

${ }^{6}$ Véanse, asimismo, los análisis sobre la obra de Fernández de los Ríos en: Bonet, 1975 y Ruiz Palomeque, 1976.

${ }^{7}$ El listado bibliográfico que se ha centrado en todas estas cuestiones a nivel local puede consultarse en los balances ya señalados de Serrano. Eligiendo una muestra de los mismos, véanse los siguientes: Monlleó, 1996; Gutiérrez Lloret, 1999; De la Fuente, 2000; Janué, 2002; Villena, 2005; Mira Abad, 2006; Sánchez Collantes, 2007; González Lorente, 2008; Higueras, 2016; Caro, 2018. 
un poder municipal sometido a una experiencia democratizadora tras los comicios locales de diciembre de 1868 (De Miguel, 2017a).

El ejercicio del poder municipal en el Sexenio es, precisamente, la temática que vehicula buena parte del presente artículo. Lo hace tanto por el propósito de calibrar el alcance que tuvo la experiencia democratizadora antes señalada como por el objetivo de detectar los rasgos que caracterizaron a la administración de una ciudad en la que, a juicio de los revolucionarios de 1868, se hacían evidentes tres cuestiones: su cambio de escala, la incompatibilidad que su modelo de gestión presentaba con respecto a las transformaciones que había observado en los decenios anteriores y la necesidad de canalizar aquellas mediante vías escasamente desarrolladas durante la etapa isabelina.

Al igual que ocurrió en Barcelona (Requena, 2013), el Sexenio fue un período en el que se produjo una toma de conciencia con respecto al nuevo orden alcanzado por el espacio urbano madrileño. Esa toma de conciencia resultó perceptible en dos momentos concretos coincidentes con los primeros instantes de una etapa política que parecía nacer con una vocación regeneradora. Primero, al certificarse la transferencia de poderes desde la Junta Superior Revolucionaria de Madrid al Ayuntamiento Popular de Madrid el 10 de octubre de 1868. El presidente de la primera institución, Joaquín Aguirre, precisó en aquella fecha los procedimientos que debían regir en una gestión municipal que hasta entonces se había mostrado «falta de iniciativas». El objetivo principal era que dicha gestión se desenvolviera en parámetros de "moralidad», dejando los cargos del Ayuntamiento en manos de "figuras capacitadas» para las tareas a asumir en términos administrativos ${ }^{8}$. Y segundo, en el bando que el alcalde del nuevo Ayuntamiento, Nicolás María Rivero, dirigió a la población un día después. En él destacaba la composición del consistorio, integrado por "hombres eminentes de todas las fracciones» que venían a representar los «intereses del municipio»; la gran responsabilidad que aquel asumía con carácter inmediato a su constitución (para resolver las «necesidades más urgentes» de una vida social «turbada en su curso ordinario») y las exigencias que se le plantearían en lo sucesivo para convertir a Madrid en «digna capital de una gran nación ${ }^{9}$.

De entre los cambios que urgían en Madrid sobresalían los materiales, los sociales y los económicos. En la primera esfera no solo cabría resaltar las propuestas de intervención urbanística de Fernández de los Ríos o las actuaciones que hicieron culminar el plan de Ensanche, sino otras que incidieron en la revitalización de la instrucción pública; en una transformación del régimen de tenencia de los cementerios que derivase en la construcción de una gran necrópolis apartada de los espacios residenciales; en una demolición de iglesias y conventos que incrementara la esponjo-

8 Archivo de Villa de Madrid, Secretaría (AVM-S), Libro de Actas del Ayuntamiento de Madrid (LAAM), sesión del 10 de octubre de 1868.

${ }^{9}$ La Iberia, 13 de octubre de 1868. 
sidad del casco antiguo; en la realización de barrios para obreros; en la reactivación de proyectos paralizados (mercados de la Cebada y Mostenses) o en la habilitación de espacios que, hasta entonces privatizados, pasaron a concebirse como zonas de esparcimiento social (parque del Buen Retiro). En el ámbito social no solo sobresalieron las medidas planteadas ante una preocupación extremada por la situación de la clase trabajadora (creación de empleo para atenuar el escenario de crisis anterior a la Revolución), sino también las que pretendían velar por la mejora de las condiciones sanitarias de la ciudad, como la reorganización del sistema de Beneficencia Municipal y de las casas de socorro. Y en el plano económico, no deben perderse de vista las iniciativas que se pusieron en liza para suprimir las cargas que asfixiaban a las clases populares, entre las que descollaba el impuesto de consumos.

Todas las cuestiones anteriormente citadas merecerían un estudio que excede los límites del presente trabajo, centrado en aspectos ligados con las políticas de policía, orden público y control social establecidas sobre el espacio urbano madrileño durante el Sexenio. El objetivo no será únicamente determinar sus características, sino también analizar los impulsos que experimentaron con las decisiones tomadas por el gobierno municipal y el gobierno civil de la provincia de Madrid tras la Revolución de 1868 escudriñando sus significados. A lo largo de esa etapa se pusieron sobre el tapete nuevos instrumentos para responder a las necesidades que en materia de higiene, abastecimiento, tránsito y seguridad habían ido surgiendo al calor de la expansión territorial y del crecimiento demográfico de la ciudad. Cobraron relevancia los discursos que incidían tanto en la importancia de incrementar el grado de intervención de las autoridades en la vida de la ciudad como en la urgencia de transformar la naturaleza de ciertos espacios urbanos y reforzar los mecanismos de control a aplicar sobre ellos. Todo ello se plasmó en actuaciones desplegadas en múltiples escenarios, introducidas por bandos, reglamentos y disposiciones que, en líneas generales, trataron de implementar nuevos estándares de disciplina, comportamiento y usos del espacio, similares a los que se establecieron en otras ciudades durante el ochocientos por vías policiales y administrativas (Storch, 1975-1976, pp. 481-509; Monkonnen, 1981; Emsley, 1983; Inwood, 1990; Ogborn, 1993; Taylor, 1997; Fraile, 2001; Lousada, 2005; Merriman, 2006, pp. 118-166; Barrie, 2010; Andersson, 2014; Barrie y Bromhall, 2016).

El artículo valorará estas cuestiones sirviéndose de la documentación tramitada por el Ayuntamiento de Madrid entre finales de 1868 y comienzos de 1873 y de la correspondencia mantenida entre la alcaldía de la citada institución, las élites locales dependientes de su autoridad y el Gobierno Civil. En el anterior escenario, interesan de manera específica las tareas realizadas por los tenientes de alcalde de los diez distritos de la ciudad y las atribuciones que asumieron los alcaldes de los diez barrios en que se dividían cada uno de los anteriores. Mientras los primeros adquirían trascendencia a la hora de garantizar la observancia de las principales normativas de policía urbana, los segundos eran figuras cruciales en el mantenimiento del orden público. 
Para el caso de los alcaldes de barrio, numerosos estudios han explorado su período de auge y declive, circunscrito desde los años posteriores al motín de Esquilache hasta 1844, cuando sus funciones fueron transferidas al Cuerpo de Protección y Seguridad creado entonces (Aguilera, 2017 y Paris, 2017). Sin embargo, quedan por explorar los cometidos que recuperaron con posterioridad y los que asumieron en el Sexenio, en el marco de la regulación social del espacio urbano y de la importancia que cobraron como conocedores del entramado comunitario de la ciudad.

\section{GOBERNAR LO COTIDIANO TRAS LA REVOLUCIÓN. EL PRETENDIDO TRÁNSITO HACIA LA LEGIBILIDAD DEL ESPACIO PÚBLICO Y LA APLICACIÓN DE NUEVAS GRAMÁTICAS EN LA POLICÍA URBANA}

De entre las muchas demandas que recibió el Ayuntamiento de Madrid en los inicios del Sexenio, principalmente vertidas desde una prensa que tras la Revolución entró en estado de efervescencia, una de las más significativas tuvo que ver con la necesidad de fortalecer las normativas sobre policía urbana ${ }^{10}$. En este escenario, se significó la urgente tarea de "llenar de forma debida» las necesidades públicas de la ciudad y emprender actuaciones que repercutieran positivamente en el bienestar y la comodidad del vecindario, acabando con las carencias que los barrios advertían en términos de orden, seguridad, higiene y ornato y con los obstáculos que se presentaban para el libre tránsito en el espacio público ${ }^{11}$. A juicio de las élites revolucionarias locales, tres eran los factores que habían incidido en el agravamiento de esos problemas. Primero, las reformas incompletas patrocinadas por los consistorios anteriores a $1868^{12}$. Segundo, la ausencia de una nómina de empleados municipales lo suficientemente extensa como para asegurar una mayor rigurosidad en el cumplimiento de las instrucciones transmitidas desde la alcaldía ${ }^{13}$. Y finalmente, la frágil cooperación que en anteriores ayuntamientos había existido entre empleados municipales, tenientes de alcalde de distritos municipales y alcaldes de barrio. Todo ello explicaba que las ordenanzas de policía urbana, aprobadas en 1847, no dejaran de ser poco menos que «letra muerta», tal y como señaló el corresponsal en Madrid del diario La France al analizar los servicios de la urbe en el contexto posrevolucionario ${ }^{14}$.

${ }^{10}$ Una reflexión sobre la policía urbana del siglo xx vinculada con los nuevos propósitos de gubernamentalidad de la ciudad en: Sánchez de Juan, 2002, pp. 126-130.

11 El Imparcial, 8 de octubre de 1868, La Iberia, 21 y 29 de octubre de 1868 y La Correspondencia de España, 22 de octubre de 1868.

12 La América, n. 20, 28 de octubre de 1868, pp. 5-6.

${ }^{13}$ La Correspondencia de España, 22 de noviembre de 1868.

${ }^{14}$ Citado en: La Época, 19 de diciembre de 1868. 
La mejora en la gestión de la policía urbana adquirió un carácter imperativo para el consistorio de Madrid desde el momento en que este se formó tras la disolución de la Junta Superior Revolucionaria. En realidad, era un objetivo que respondía al mismo patrón que guiaba el conjunto de proyectos que para la transformación material de la ciudad se estaba presentando en esos momentos. Como posteriormente se señaló en el Boletín Oficial del Ayuntamiento de Madrid, el consistorio salido de la Revolución debía tomar caminos opuestos a los que hasta entonces siguieron antiguos concejos de la ciudad ${ }^{15}$. Uno de ellos era el de acompañar los cambios cuantitativos que había ido experimentando la urbe en los decenios anteriores a 1868 con otros cualitativos, para así generar la definitiva transición entre el Madrid del Antiguo Régimen y el Madrid moderno. Esa transición debía ir acompañada por otra paralela entre una ciudad opaca y una ciudad transparente, siguiendo la terminología de Requena para Barcelona en el siglo XIX (Requena, 2003, pp. 827-844).

Fue el consistorio formado tras las elecciones municipales de 1868 el que trataría de avanzar por el camino de transición entre dos ciudades diferenciadas. Extrapolando los asertos de Fraser sobre la política municipal británica del siglo XIX para el caso de Madrid (Fraser, 1976, pp. 154-177), aquella corporación local surgida del primer ensayo del sufragio universal masculino debía justificarse a sí misma contribuyendo a lo que entendía como el progreso de la comunidad urbana. Para ello, se pusieron en marcha una serie de proyectos. El primero de ellos fue el de amplificar la nómina de empleados de policía urbana. A juicio de Nicolás María Rivero, el cuerpo que había heredado la corporación municipal de la etapa isabelina era escaso para una ciudad de las características de Madrid y estaba pobremente organizado y disciplinado. La falta de personal se abordó incrementando su número. Se duplicó nada más verificarse los comicios locales, pasando de doscientos a cuatrocientos empleados, a los que se sumarían otros cien tras las decisiones adoptadas por el consejo municipal el 15 de febrero de $1869^{16}$. Asimismo, en la sesión ordinaria celebrada en esa fecha el consistorio fijó reglas para solventar los mencionados problemas de organización y disciplina. Estos últimos ya se habían podido advertir por algunas autoridades en las semanas previas. Una de las más expresivas con respecto al anterior punto fue Fernando Hidalgo Saavedra, teniente de alcalde del distrito de Congreso, que culpó a los agentes de policía urbana no solo del «deplorable» estado que presentaban algunas calles de esa demarcación, sino también de la insubordinación que mostraban hacia su autoridad ${ }^{17}$.

${ }^{15}$ Boletín Oficial del Ayuntamiento de Madrid, n. 1, 8 de marzo de 1869, p. 1.

${ }^{16}$ AVM-S, LAAM, sesión ordinaria del 15 de febrero de 1869.

17 AVM-S, Actas de juntas de los tenientes de alcalde de Madrid, 27 de enero de 1869, sig. 18-254-6. 
En función de lo dictaminado en el señalado pleno municipal del 15 de febrero de 1869, todos los integrantes del cuerpo de policía urbana debían tener una conducta intachable y unos antecedentes políticos que permitieran reconocer tanto su adhesión a la causa revolucionaria como sus compromisos con ella. Paralelamente, se instó a la necesidad de establecer una estrecha cooperación entre los visitadores, celadores y los vigilantes pertenecientes a ese cuerpo y los tenientes de alcalde de los distritos y los alcaldes de barrio, enfatizándose la relevante tarea que estos debían asumir a la hora de informar sobre las deficiencias que presentaba cada espacio urbano ${ }^{18}$.

Apenas un mes después de que se oficializaran las disposiciones relativas al personal de policía urbana, el Ayuntamiento de Madrid redactó un reglamento en el que precisaba las normas que en ese escenario harían cumplir los agentes de la autoridad. La retórica que encabezaba el bando en el que se publicaron aquellas directrices no se alejaba de la utilizada por anteriores consistorios, visible tanto en el Reglamento de Policía Urbana de $1841^{19}$ como en las ya mencionadas ordenanzas para la policía urbana de Madrid de $1847^{20}$, publicadas bajo el auspicio de las iniciativas de Ramón de Mesonero Romanos ${ }^{21}$. En el documento oficial, la alcaldía determinaba dedicar "toda la eficacia de acción» al servicio, por la manera en la que aquel quedaba íntimamente relacionado con «el aseo y la limpieza de las calles y plazas, con la comodidad de los vecinos y con la higiene pública». Sin embargo, el bando también expresaba la cesura a imponer con respecto a la gobernanza urbana de la era isabelina:

La incuria y abandono en este ramo del servicio municipal (policía urbana) podría ser tolerable en épocas y sistemas de triste y afrentoso recuerdo, en los cuales el desorden en la vida común y el repugnante aspecto de las poblaciones estaban en perfecta armonía con el embrutecimiento moral. Empero, en los pueblos que, como el nuestro, han sabido elevarse a toda la altura de la civilización, los adelantos de la higiene y las reglas de la decencia deben exteriorizarse en los actos y las costumbres de la vida material, porque la ilustración y la libertad, que es su consecuencia, no pueden existir rodeadas de inmundicia ${ }^{22}$.

${ }^{18}$ AVM-S, LAAM, sesión ordinaria del 15 de febrero de 1869.

19 AYUNTAMIENTO DE MADRID, Reglamento de Policía Urbana para la muy honorable Villa de Madrid, Madrid, s. e., 1841.

20 AYUNTAMIENTO DE MADRID, Ordenanzas de policía urbana y rural para la Villa de Madrid y su término, Madrid, s. e., 1847.

${ }^{21}$ Ezquiaga, 1990, pp. 149-156 y Anguita, 1992, pp. 463-482.

22 AVM-S, Disposiciones de policía urbana del Ayuntamiento Popular de Madrid, 12 de marzo de 1869, sig. 4-406-6. 
El Reglamento de Policía Urbana publicado por Rivero contenía cincuenta artículos en los que se explicitaban normas asociadas a múltiples temáticas. Los de carácter general evidenciaban el objetivo de corregir determinados comportamientos poblacionales, en aras de crear un marco depurado de organización y regulación de la ciudad. Hacían alusión a cuestiones relacionadas con la limpieza urbana (prohibiciones de depositar basura en calles, plazas y portales y obligación de los vecinos de bajar la misma al paso de los carros y barrenderos del Ayuntamiento); la higiene pública (prohibición de orinar en la vía pública salvo en recipientes colocados para tal efecto y de sacudir desde los balcones ruedos y alfombras); el libre tránsito por las aceras (prohibición de hacer colchones, partir leña o descargar serones de carbón en la calle) y el ornato (prohibición de estacionamiento en calles, plazas y paseos de barberos para afeitar y cortar el pelo o de mujeres para peinarse, lavar y espulgar animales domésticos). De un modo más específico, el reglamento contenía disposiciones relativas a puestos públicos (prohibiciones para vendedores ambulantes relativas a la exposición de sus géneros en determinados puntos de la vía pública y al pregón de los mismos sin contar con licencias de la alcaldía), a las fuentes de vecindad (prohibición de lavar ropas y arrojar inmundicias y respeto estricto de la provisión de agua tanto para la población como para los aguadores de oficio), a la salubridad pública conectada con la venta de comestibles (observación del mayor aseo en los locales dedicados a la expedición de carnes, prohibición de venta de reses enfermas o sacrificadas en casas de matanza clandestinas, prohibición de venta de leche mezclada con agua) y a la preservación de la seguridad y la comodidad en el desenvolvimiento cotidiano por las calles (prohibiciones de encender braseros, herrar caballerías o conducir perros sin bozal o cordel $)^{23}$.

Las normas de policía urbana anteriormente expresadas iban acompañadas de advertencias relativas a la penalidad en que se podía incurrir como consecuencia de su incumplimiento. En líneas generales, la contravención de las disposiciones conllevaba el abono en metálico de un escudo de multa, cantidad que se multiplicaría por cinco y por diez en caso de primera y segunda reincidencia respectivamente. Para las reglas de salubridad relacionadas con la venta de alimentos y la seguridad en la vía pública, se exigiría el pago de diez escudos, que podría ascender a treinta y cincuenta en subsiguientes incumplimientos. Finalmente, se dictaminaba un día de arresto por escudo no pagado para los infractores que no satisficieran las multas. Todo ello respondía a un sentir generalizado expresado por los concejales a principios de 1869: mitigar el estado de abandono de una capital que, lejos de expresar señales de civilización y cultura en el comportamiento de sus habitantes,

23 Íbid. 
daba «asco y vergüenza» por la forma en que proliferaban «costumbres que tenían mucho de inmoralı ${ }^{24}$.

En líneas generales, las disposiciones sobre policía urbana ejemplificaban lo que el poder municipal de Madrid tipificaba no solo como lo esperado, sino también como lo consentido, en la ciudad nueva del Sexenio. Las reglas allí compiladas dejaban entrever la intencionalidad de proceder a una reconfiguración social y física del espacio urbano, transformando usos que entonces seguían prevaleciendo y desterrando los que se juzgaban más próximos a la identidad rural (partir leña en aceras, herrar y atar caballerías en la vía pública, etc) que a la renovada identidad urbana que se buscaba establecer, basada en una regulación de la vida pública que enfatizaba la «virtud cívica» (Barrie, 2010, pp. 45-65). Aplicando las interpretaciones de Martínez Lorea, deudoras de las tesis sobre producción del espacio de Lefebvre (2013 [1974]), se hacía evidente el reforzamiento de una idea: construir un escenario urbano de lo tolerable, alejando lo que implicara distorsiones en su orden y legibilidad (Martínez Lorea, 2013, p. 22).

Los objetivos globales del reglamento analizado se complementaron con los que se fueron exponiendo en bandos inmediatamente sucesivos. Junto a los procedimientos normativos que enfatizaban el rol del ampliado cuerpo de policía urbana, los discursos y las palabras buscaban jugar un papel más importante en la gestión del espacio físico, como ha señalado Doyle (2007, p. 19), condenando determinadas prácticas sociales advertidas en él. Así, el Ayuntamiento de Madrid planteó la necesidad de racionalizar una circulación que progresivamente iba intensificándose, registrando de manera rigurosa los carruajes que transitaban por la ciudad y ejecutando una división más clara entre los de servicio público (carros y camiones de mudanzas), los de servicio particular (de fabricantes, almacenistas y comerciantes) y los destinados al alquiler. Para las tres tipologías se fijaban las cuotas que debían satisfacer al municipio, las licencias de las que se debían proveer previo contacto con la alcaldía y los puntos de estacionamiento a los que debían atenerse ${ }^{25}$. Poco después, se oficializaron prescripciones para proteger la flora y la fauna de paseos, parques y jardines públicos, fijando prohibiciones amparadas por el Código Penal para acabar con los «hechos punibles» que en algunos de ellos tenían lugar ${ }^{26} . Y$ de manera paralela, fueron publicándose disposiciones que recordaban algunos de los principales artículos incluidos en las ordenanzas de 1847, como los relativos al ejercicio de actividades de caza y pesca (restricciones prohibitivas entre los meses de marzo y julio en cada año) ${ }^{27}$, a la

${ }^{24}$ AVM-S, LAAM, sesión ordinaria del 12 de enero de 1869.

${ }^{25}$ AVM-S, Disposiciones de policía urbana del Ayuntamiento de Madrid, 1869, sig. 4-406-8.

${ }^{26}$ AVM-S, Bando de la alcaldía por el que se prohíbe coger flores en jardines y parques, sig. 4-406-12.

${ }^{27}$ AVM-S, Bando de la alcaldía sobre el ejercicio de caza y pesca, 29 de marzo de 1869, sig. 4-406-10. 
temporada de baños en el Río Manzanares (reglas de seguridad para usuarios) ${ }^{28}$ o a la extinción de perros vagabundos (en épocas en las que su número fuera excesivo y viniera acompañado de episodios de hidrofobia) $)^{29}$.

El análisis de la correspondencia mantenida entre la alcaldía de Madrid, los tenientes de alcalde a nivel de distrito y los alcaldes de barrio refleja la trascendencia que cobraron los anteriores objetivos. Tras la publicación del Reglamento de Policía Urbana del 12 de marzo de 1869, Nicolás María Rivero envió comunicaciones a los tenientes de alcalde de los diez distritos de la ciudad para solicitarles el seguimiento de una tarea concreta: velar incesantemente por la exacta observancia de todas las prescripciones contenidas en el documento, para así conseguir «la completa extinción de los abusos que con sentimiento he notado en algunos puntos de la capital $»^{30}$. Los tenientes de alcalde mantenían, a su vez, un enlace directo con los ya citados alcaldes de barrio y con el máximo responsable del Cuerpo de Policía Urbana de Madrid, esto es, su visitador general. Esta última era la figura que en última instancia se encargaba de transmitir órdenes precisas a vigilantes y celadores para castigar económicamente o detener a los infractores de las normativas de policía urbana ${ }^{31}$. A su vez, el visitador general redactaba los partes diarios de las denuncias que se tramitaban en el anterior concepto, especificando su tipología y las cantidades económicas recaudadas a través de las multas. Todo ello era finalmente remitido a la corporación municipal, que se encargó de dar a conocer estas actuaciones a la opinión pública mediante su compilación estadística, publicada con periodicidad semanal en el Boletín Oficial del Ayuntamiento de Madrid.

${ }_{28}$ AVM-S, Bando de la alcaldía sobre la temporada de baños en el Río Manzanares, 10 de junio de 1869, sig. 4-419-8.

${ }^{29}$ AVM-S, Bando de la alcaldía sobre perros e hidrofobia, 23 de abril de 1869, sig. 4-419-10.

${ }^{30}$ AVM-S, Correspondencia entre el alcalde de Madrid, Nicolás María Rivero, y Simón Pérez, teniente de alcalde del distrito de Centro. 16 de abril de 1869, sig. 13-220-2.

31 AVM-S, Correspondencia entre el teniente de alcalde del Ayuntamiento de Madrid, Manuel María José de Galdo, y el visitador general de policía urbana de Madrid, 22 de marzo de 1869, sig. 14-20-9. 
Gráfico 1. Tipología de las multas tramitadas por el Cuerpo de Policía Urbana de Madrid en marzo y abril de 1869

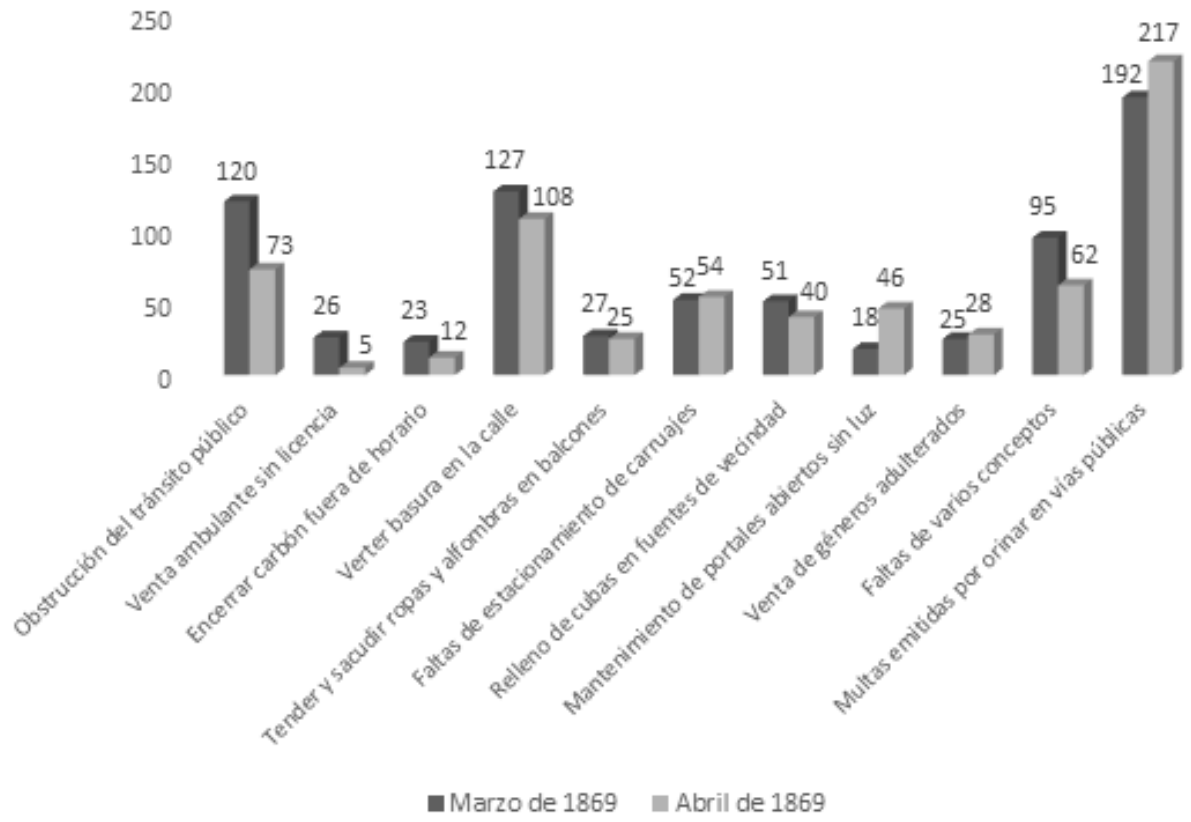

Fuente: Archivo de Villa de Madrid, Secretaría (AVM-S), Partes diarios del visitador general de policía urbana de las denuncias hechas por faltas en los distritos de Madrid, signatura 5-373-1.

La significación de la publicidad de las infracciones que se cometían en materia de policía urbana y en el seguimiento de las ordenanzas de 1847 no debe pasarse por alto. Respondía a un criterio que no era inocente: arrojar luz sobre todas las actividades desarrolladas por el gobierno local, hasta entonces «encerradas en el seno de la corporación», para ponerlas "a conocimiento de todos los ciudadanos» ${ }^{32}$. 0 , dicho de otra manera, a la conveniencia de generar una correspondencia entre los asuntos tratados en el Ayuntamiento y los orígenes «populares» de este último ${ }^{33}$. La indicación del tipo de contravenciones de las normas municipales y la señalización de sus infractores, con nombres y apellidos para casos relacionados con la salubridad pública, suponía una novedad que perdería trascendencia en los consistorios de finales del siglo $X I X^{34}$.

Si se va de lo general a lo particular, los propósitos que el gobierno municipal de Madrid mostró a la hora de fortalecer las normativas de policía urbana y lograr una mayor rigurosidad en su cumplimiento se materializaron (o así trataron de hacerlo)

${ }^{32}$ Boletín Oficial del Ayuntamiento de Madrid, n.o 1, 8 de marzo de 1869, p. 1.

33 Íbid.

${ }^{34}$ De Miguel, 2017b. 
con especial intensidad en dos escenarios. El primero de ellos contemplaba actuaciones relacionadas con el objetivo de adaptar el espacio urbano a pretensiones específicas de ornato, decoro y estética. Un apartado en el que podríamos destacar las iniciativas planteadas en la venta ambulante. Por su parte, el segundo escenario entroncaba con tareas que aludían a otras necesidades, como la de garantizar una mayor seguridad para la población en el desarrollo de su vida cotidiana, especialmente en lo que respecta al consumo de alimentos.

La venta ambulante pasó a ser consentida por el Ayuntamiento de Madrid a partir de 1852, previo pago de cuotas que implicaban la concesión de licencias para los interesados en dedicarse a esa actividad. El historiador Nieto Sánchez ha explicado con solvencia ese margen de tolerancia, especialmente para el Bienio Progresista, ateniéndose a la necesidad del consistorio de paliar una situación hacendística deficitaria (Nieto Sánchez, 2004). Al calor de esa tolerancia, la actividad comercial itinerante experimentó un crecimiento muy significativo, paralelo al que advirtió la desarrollada en establecimientos fijos. Esta tendencia, reproducida también en otras grandes ciudades europeas al calor de los flujos migratorios rurales (Phillips, 1992, pp. 53-76 y Calaresu y Van den Heuvel, 2016), dio pábulo a un incremento de las preocupaciones mostradas por los consistorios del Sexenio, delimitadas por tres puntos: la forma en que la venta ambulante se expandía fuera del marco legal estipulado por el municipio, la manera en la que perjudicaba al comercio fijo mediante una competencia supuestamente ilícita y las molestias que ocasionaba en la planificación de un espacio urbano a racionalizar ${ }^{35}$.

Tal y como atestigua la documentación tramitada por las tenencias de alcaldía, el Sexenio fue una época en la que los comerciantes fijos y ciertos sectores del vecindario se pronunciaron en contra de la actividad mercantil itinerante, reivindicando su estricta regulación ${ }^{36}$. En la mayoría de las ocasiones, esa regulación se invocaba en función de la ya señalada competencia ilícita y de las prácticas supuestamente deshonestas de los vendedores ambulantes. Así lo hizo Vicente Fraile, propietario de una cacharrería en el número 119 de la calle de Toledo, mediante carta dirigida al teniente de alcalde del distrito de la Latina. Fraile iniciaba su comunicación aduciendo la honradez con la que desarrollaba su negocio y la forma en la que cumplía con el pago de las cuotas contributivas en materia comercial. A renglón seguido, el pequeño industrial mostraba su preocupación por el tinglado que venía operando en las semanas previas en la acera situada frente a la casa contigua. Si bien el dueño de ese puesto disponía de una licencia concedida por el Ayuntamiento, no

${ }^{35}$ Idénticas inquietudes generaba la venta ambulante en el ámbito internacional durante el siglo XIX, como demuestran los estudios de: Bluestone, 1991, pp. 68-92; Revest, 2002; Geyzen, 2012, pp. 53-64; Acerbi, 2017 y Kelley, 2019.

${ }^{36}$ Para un análisis de las luchas entre comerciantes fijos y ambulantes en el ámbito europeo durante el ochocientos, véase: Chatelain, 1971, pp. 359-384. 
se dedicaba a la actividad que se había consignado en la misma (venta de agua de cebada). Por el contrario, ofertaba «cacharros y otros objetos peculiares de la industria» que generaban un «notable perjuicio» para los intereses económicos de Fraile. Además, el citado tinglado no era gestionado por el dueño de la licencia, con lo que se incurría en un traspaso de la actividad a terceras personas que faltaba a lo dispuesto en las ordenanzas de $1847^{37}$.

Las alegaciones de Fraile eran un calco de las que manifestaban otros industriales y comerciantes fijos por toda la ciudad. Ahí se encontraban los taberneros del señalado distrito de la Latina, que solicitaron a los alcaldes de los diez barrios de esa demarcación la desaparición de los puestos ambulantes que se establecían en calles y plazas «sin autorización y sin contribuir al sostenimiento de los impuestos que el municipio tenía reconocidos» ${ }^{38}$. O los propietarios de las vaquerías del distrito de Hospicio, que sistemáticamente denunciaron los perjuicios que les ocasionaba la gran afluencia de «lecheros que desde varios pueblos limítrofes a esta Corte circulan diariamente como tales ambulantes por sus calles, vendiendo sin licencia ${ }^{39}$. $Y$ no conviene olvidar a quienes contaban con puestos fijos en los mercados al aire libre, como el de la Plaza de San Miguel o el que provisionalmente se enclavó en la Plaza de San Millán, durante la construcción del mercado de la Cebada. Los que allí ejercían su actividad protestaban por la presencia de los «muchos vendedores ambulantes que poblaban las cercanías de las plazuelas de Madrid», sin pagar cuotas y perjudicándoles en su condición de contribuyentes, al dejarles desprovistos de «las ventas que sin ellos tendrían ${ }^{40}$.

Al mismo tiempo, el Ayuntamiento de Madrid, a través de las tenencias de alcaldía, insistió en fiscalizar con un mayor rigor los puestos itinerantes exponiendo consideraciones que incidían en la interceptación de la vía pública y la preservación del ornato, la higiene y la moral en el espacio urbano. En no pocas ocasiones, esas consideraciones también venían determinadas por quejas de la población. Así, por ejemplo, la interceptación de la vía pública fue denunciada por Pablo Fernández Iz-

37 AVM-S, Comunicaciones sobre varios particulares. Tenencia de alcaldía del distrito de la Latina. Denuncia sobre el ejercicio de venta ambulante de Vicente Fraile, 26 de abril de 1871, sig. 14-23-3.

${ }^{38}$ AVM-S, Comunicaciones de policía urbana. Tenencia de alcaldía del distrito de la Latina. Denuncia sobre venta ambulante dirigida a los alcaldes de barrio por los almacenistas de vinos establecidos con casa abierta en el distrito, 15 de octubre de 1868, sig. 14-20-7.

${ }^{39}$ AVM-S, Oficios de secretaría de la tenencia de alcaldía del distrito de Hospicio. Carta de los propietarios de vaquerías del distrito al teniente de alcalde, 18 de mayo de 1869, sig. 13-3912.

${ }^{40}$ AVM-S, Comunicaciones del Ayuntamiento de Madrid. Tenencia de alcaldía del distrito de la Latina. Denuncia relativa a puestos y cajones de la vía pública, 10 de noviembre de 1870, sig. 14-21-5 y AVM-S, Documentación de policía urbana. Tenencia de alcaldía del distrito de Centro. Denuncia de venta ambulante en plazuelas, 1 de septiembre de 1872, sig. 13-222-2. 
quierdo, un farmacéutico afincado en la calle de la Ruda que solicitó la intervención de las autoridades ante los abusos que cometían las verduleras instaladas en esa vía pública, ocupando con sus puestos la portada de su establecimiento e imposibilitando la entrada de sus clientes ${ }^{41}$. En la línea de la higiene, el decoro y la moral cabrían situar los escándalos que significaron los habitantes de la calle de Pelayo unos años antes, provocados por vendedores de comestibles «sin sitio limitado en la vía pública» que no permitían ni «el reposo del vecindario en sus lechos» ni la «salida y entrada en las tiendas y edificios de la vía pública», a lo que había que sumar «las palabras subversivas, insultantes y obscenas» que proferían ${ }^{42}$. Todas ellas eran opiniones que adquirían mayor resonancia si cabe en los espacios más céntricos y en el barrio de la Puerta del Sol, si se observan las palabras de su alcalde, Felipe Fernández, en 1872. La comunicación que entonces dirigió a la tenencia de alcaldía del distrito de Centro reivindicaba la expulsión de los vendedores ambulantes de aquella zona, sobre la base de argumentos que incidían en la distorsión que aquellos generaban en un espacio público respetable y cívico:

En vista de las repetidas quejas que diariamente se me comunican por varios vecinos del barrio (...) sobre los diferentes individuos que se dedican a la venta ambulante, y teniendo en cuenta las palabras que en sus conversaciones suelen emplear, ofensivas al decoro y a la moral, he creído de mi deber como alcalde de barrio transmitir los deseos de varios vecinos del barrio, en mi concepto muy atendibles, por si estima conveniente dictar alguna disposición que tienda a evitar abusos, debiendo tener muy en cuenta que la Puerta del Sol, por sus circunstancias especiales, y por ser el punto más céntrico y transitado de esta capital, debe ser objeto de una exquisita vigilancia. Si como espero que usted tome en consideración las razones expuestas por el que suscribe, por ser hijas de una necesidad por todos sentida, estoy seguro de que los vecinos del barrio aplaudirían una medida que, sobre ser justa, tiende a hacer desaparecer ciertas clases de gentes que por sus trazas y modales no debieran estar en un punto por donde transitan las personas más escogidas de la sociedad ${ }^{43}$.

Las decisiones que el gobierno municipal tomó para regularizar la venta ambulante quedaron condensadas en dos reglamentos, publicados el 13 de julio de 1872 y el 22 de noviembre de 1873 respectivamente. En ambos casos, se insistía en la fijación de obligaciones unívocas para los comerciantes itinerantes: proveerse de las

${ }^{41}$ AVM-S, Circulares del Ayuntamiento de Madrid. Tenencia de alcaldía del distrito de la Latina. Denuncia sobre la actividad de verduleras, 27 de junio de 1872, sig. 14-23-3.

${ }^{42}$ AVM-S, Comunicaciones de policía urbana. Tenencia de alcaldía del distrito de Hospicio. Carta de los vecinos del barrio de Pelayo al teniente de alcalde, 16 de febrero de 1869, sig. 13378-2.

43 AVM-S, Documentación de policía urbana. Tenencia de alcaldía del distrito de Centro. Comunicación del alcalde de barrio de Puerta del Sol al teniente de alcalde, 13 de febrero de 1872, sig. 13-222-2. 
licencias expedidas por el consistorio previo pago de los derechos a los que debían acogerse en función de la tipología de los artículos vendidos (seis pesetas anuales para los que transportaban mercancías a mano, doce pesetas anuales para los que lo hacían por caballería menor y quince pesetas anuales para quienes utilizaban caballería mayor); exhibir en sus puestos las licencias para la comprobación de su actividad; dotar a los puestos de medidas concretas para no entorpecer el tránsito público; mantener unas normas de salubridad; utilizar pesas y medidas para evitar el fraude en el despacho de artículos; no ceder el control del tinglado a terceros, etc. En cualquier caso, todas estas medidas se justificaban sistemáticamente sobre la misma triada argumental ya señalada (contribución de todas las formas comerciales a las cargas municipales, respeto del comercio fijo y preservación del libre tránsito público), conectada con el objetivo de corregir el carácter «imperfecto, caótico y desordenado $»^{44}$ de una venta ambulante que se definía como «impropia de una culta capital» y de contener su presencia en aquellos espacios definidos por la confluencia de sectores burgueses y acomodados ${ }^{45}$.

En lo que respecta a las actuaciones realizadas por el gobierno municipal de Madrid a la hora de hacer progresar la seguridad de la población en el desarrollo de su vida cotidiana, se puso un énfasis significativo en las condiciones de higiene y salubridad con que se expendían los alimentos. A diferencia de Barcelona, la capital española no contaba con un laboratorio de higiene dedicado al análisis de los anteriores ${ }^{46}$. La ciudad tampoco se había sumado a la ola sanitaria que desde mediados del ochocientos venía denunciando el imperfecto carácter de la fiscalización tradicional de subsistencias a la hora de combatir su creciente degeneración (visible en fenómenos cada vez más extendidos como el fraude, la adulteración y la falsificación $)^{47}$. Sin embargo, la carencia de una institución especializada en el control de alimentos, identificadora de la función social que en ese proceso debían cumplir médicos, veterinarios y químicos, no significaba que no se estuviera tomando una cierta conciencia con respecto al reforzamiento del papel que el municipio debía jugar en el mismo.

44 Estos calificativos sobre la venta ambulante eran idénticos a los aplicados en algunas de las principales ciudades europeas a mediados del siglo XIX. Véase un ejemplo en: Green, 1982, pp. 129-151.

45 Ayuntamiento de Madrid, Reglamentos Municipales, 1866-1917, Madrid, Imp. Municipal, 1917, pp. 1148-1150.

46 Para una panorámica global sobre el proceso de creación de dichos laboratorios a escala nacional, véanse: Perdiguero, 2001, pp. 46-51 y Guillem-Llobat y Perdiguero, 2014, pp. 117-128.

${ }^{47}$ Con carácter ejemplificador, véanse los trabajos compilados en: Burnett y Oddy, 1994. Asimismo, los estudios sobre regulación de alimentos de Derek J. Oddy, Vera Hielhozer, Peter Scholliers y Alessandro Stanziani para Londres, Alemania, Bruselas y París reunidos en: Atkins, Lummel y Oddy, 2007. 
Como fue habitual tanto en épocas que precedieron al Sexenio como con posterioridad al mismo, la venta del pan y el fraude que en su peso podían cometer los tahoneros durante su proceso de expedición tuvieron un protagonismo destacado en los debates municipales (De Miguel, 2017b). De tal problema ya se hacía eco el Reglamento de Policía Urbana del 12 de marzo de 1869. Sin embargo, las premisas a seguir en ese apartado apenas mostraron diferencias con respecto a las emitidas por anteriores gobiernos locales. Si acaso, se excitó la vigilancia en la fabricación del artículo y la supervisión de sus condiciones en las etapas en que proliferaban las quejas del vecindario con respecto al fraude ${ }^{48}$. Como en otros apartados de la policía urbana, los tenientes de alcalde eran los máximos responsables de verificar el correcto peso del pan. Las actas de sus reuniones revelan una praxis que siempre se basó en una doctrina cuatripartita: ejecutar tareas de repeso fuera de las tahonas, precisar sistemáticamente a los tahoneros la instalación de básculas en sus obradores, proceder con el mayor rigor contra los que incumplieran las ordenanzas municipales (mediante multas) y decomisar todo el pan afectado por el fraude para distribuirlo entre los establecimientos benéficos de la ciudad y entre los alcaldes de barrio, los cuales encargarían de racionarlo entre los habitantes más pobres de su demarcación y entre las casas de socorro ${ }^{49}$.

Más incisivas fueron las políticas que desde la corporación municipal se siguieron para hacer frente a otros problemas sanitarios relacionados con la alimentación, como los derivados del consumo de carnes procedentes de reses enfermas y leche adulterada, especialmente desde el momento en el que se tuvo constancia del principio de una epidemia de fiebre tifoidea en Madrid que se vinculó a esos factores desde las concejalías ${ }^{50}$. En lo que respecta al primer apartado, ya había unos precedentes reglamentarios de cierta significación. En 1834 se había reconocido el carácter fundamental de los mataderos para la inspección de carnes y para el control de las enfermedades que pudieran transmitirse a través del consumo de animales, declarándose obligatorios para los municipios de más de 2.000 habitantes en 1859. Paralelamente, también se habían fijado reglamentos para el régimen interior de esos recintos ( 1840 y 1847 ) y para la actividad de quien en ellos ejercían como inspectores veterinarios. Durante el Sexenio, las tenencias de alcaldía de los distritos incidieron no solo en el seguimiento de esas normativas, sino, sobre todo,

48 AVM-S, Circular de la alcaldía de Madrid a las tenencias de alcaldía de distrito para ejercer la vigilancia sobre la fabricación del pan, 11 de mayo de 1869, sig. 13-220-2 y AVM-S, Comunicaciones del Ayuntamiento de Madrid. Tenencia de alcaldía del distrito de la Latina. Comunicación de la alcaldía de Madrid al teniente de alcalde sobre pan y salubridad pública, 7 de mayo de 1869, sig. 14-20-9.

49 AVM-S, Actas de juntas de los tenientes de alcalde de Madrid, 24 de mayo de 1870, sig. 18-254-6 y AVM-S, Documentación sobre vigilancia de la fabricación y expedición del pan, sig. 5-330-5 (1870), 5-330-6 (1869) y 5-330-11 (1871).

${ }^{50}$ AVM, LAAM, sesión ordinaria del 30 de marzo de 1869. 
en la vigilancia de las carnes que entraban en la capital, a fin de que estas últimas fuesen siempre sacrificadas en el matadero y una vez se hubiese efectuado su reconocimiento facultativo.

Lo anteriormente señalado se tradujo en un incremento de la vigilancia de las reses que llegaban a la ciudad y en la proyección de una supervisión más depurada con respecto a los mataderos clandestinos tanto del interior del término municipal como de las localidades colindantes con aquel. Al margen de la participación que en este proceso tenían los tenientes de alcalde de los distritos, encargados de la imposición de multas y de los decomisos, destacó la organización de rondas especiales de fiscalización de carnes formadas por integrantes del Cuerpo de Policía Urbana, las cuales quedaban a disposición de las instrucciones transmitidas por el comisario del Matadero Municipal ${ }^{51}$.

En lo que respecta al consumo y al suministro de leche, Madrid carecía de una regulación específica que fuera más allá de lo visible en Barcelona. Al igual que en la capital catalana, y de acuerdo con los análisis de Hernández Adell, las prescripciones relacionadas con la venta del producto aludían a las necesidades de separar los tipos de leche en función de su procedencia, de referenciar sus condiciones cualitativas y de prohibir el aguado (Hernández Adell, 2012, pp. 295-296). En el caso de Madrid, el Sexenio fue una etapa en la que fueron recurrentes los bandos de policía urbana que restringían la expedición de leche de oveja durante las temporadas más calurosas del año, praxis que, sin embargo, no evidenciaba ruptura alguna con respecto a la seguida por anteriores gobiernos municipales ${ }^{52}$. Sí ofrecía novedades, por el contrario, la intensificación de la vigilancia seguida por el Ayuntamiento con respecto a las vaquerías, cada vez más presentes en el interior de la población (Hernández Adell, 2012, pp. 59-60).

${ }^{51}$ AVM-S, Bando de la alcaldía de Madrid sobre venta de cordero, 31 de marzo de 1869, sig. 4-419-17; AVM-S, Juicios de policía urbana y gubernativos civiles. Tenencia de alcaldía del distrito de Centro. Circular de la tenencia de alcaldía del distrito de Centro sobre vigilancia de mataderos, 9 de noviembre de 1869, sig. 13-220-2; AVM-S, Comunicaciones del Ayuntamiento de Madrid a la tenencia de alcaldía del distrito de la Latina. Circular de la alcaldía de Madrid sobre vigilancia de carnes, 24 de septiembre de 1869, sig. 14-20-9; AVM-S, Comunicaciones del Ayuntamiento de Madrid a la tenencia de alcaldía del distrito de la Latina. Circular de la alcaldía de Madrid sobre organización de rondas de vigilancia sobre la introducción de carnes, 3 de agosto de 1869, sig. 14-20-9; AVM-S, Bando de la alcaldía de Madrid sobre introducción de carnes muertas, 30 de noviembre de 1869, sig. 14-21-5; AVM-S, Circulares del Ayuntamiento de Madrid. Tenencia de alcaldía del distrito de la Latina, Quejas sobre introducción de carnes, 7 y 16 de octubre de 1872, sig. 14-23-3. Asimismo, véanse los debates que sobre la introducción y venta de carnes tuvieron lugar en: AVM-S, Actas de juntas de los tenientes de alcalde de Madrid, 21 de diciembre de 1869 y 12 de julio de 1871, sig. 18-254-6.

52 AVM-S, Bando de la alcaldía de Madrid decretando la prohibición de la venta de leche de oveja, 30 de junio de 1869, sig. 4-419-1. 
En el anterior punto, el Ayuntamiento de Madrid contó con la cooperación de la Junta Municipal de Sanidad, constituida con carácter permanente el 10 de marzo de 1869 y formada por diez vocales (uno por cada distrito) ${ }^{53}$. Junto a las recomendaciones que la junta transmitió a las autoridades locales desde su creación (examen riguroso de las casas de los pobres a nivel de barrio por parte de los médicos de la Beneficencia Municipal, limpieza constante del alcantarillado, mayor rigor en la limpieza de las calles, nula permisividad para la acumulación de basuras, cumplimiento de las ordenanzas respecto a la construcción de nuevas casas), descollaban las advertencias que sus integrantes consignaron para reconocer las vaquerías de la ciudad, de cara a cerrar las que no reuniesen las debidas condiciones de higiene, capacidad y cubicación o a corregir las faltas advertidas en esos términos ${ }^{54}$.

El proceso de inspección de las vaquerías existentes en Madrid exigió una cooperación a tres bandas en la que participaron la Junta Municipal de Sanidad, las tenencias de alcaldía de los distritos y los arquitectos facultativos del Ayuntamiento. Un ejemplo de su funcionamiento se puede encontrar en el distrito de Hospicio a la altura de 1871. Los informes que se elaboraron en esa demarcación precisaban con detalle las carencias que ofrecían los establecimientos de la tipología señalada, consignando el número de reses encerradas para confrontarlo después con el número que debía permitirse en función de su capacidad, si existía o no necesidad de operaciones significativas de limpieza o de blanqueo, si debían inutilizarse determinadas partes de los locales, etc. Todas estas valoraciones culminaban con unas consideraciones finales que generalmente apuntaban a una doble direccionalidad: bien la continuidad del establecimiento, bien su cierre inmediato en función de si se corregían, o no, esas deficiencias ${ }^{55}$.

Al control de la venta ambulante y de los alimentos habría que añadir otros muchos apartados a los que el poder municipal del Madrid del Sexenio buscó imprimir una mayor vigilancia. La vivienda y sus deficiencias exteriores e interiores (aireadas por la prensa durante la etapa isabelina y denunciadas en los estudios de figuras pioneras de la doctrina higienista como Méndez Álvaro) (Alcaide, 1999 y Huertas, 2002), tuvieron, por ejemplo, un notable protagonismo en las líneas de actuación

${ }^{53}$ Su creación se plantea como medida urgente por decisión de los tenientes de alcalde de Madrid, en aras de ayudar a las tareas realizadas por los alcaldes de barrio para la preservación de la higiene pública. En: AVM-S, Actas de juntas de los tenientes de alcalde de Madrid, 20 de febrero de 1869, sig. 18-254-6.

${ }^{54}$ AVM-S, Sobre las propuestas de la Junta Municipal de Sanidad del Ayuntamiento de Madrid para que se adopten ciertas prescripciones encaminadas a mejorar el servicio sanitario de la ciudad, 24 de marzo de 1869, sig. 7-204-30 y AVM-S, Actas de la Junta Municipal de Sanidad, 1868-1872, sig. 7-71-1.

55 AVM-S, Documentación de policía urbana. Tenencia de alcaldía del distrito de Hospicio, Informe sobre el proceso de inspección de vaquerías, 19 de noviembre de 1871, sigs. 13-392-2 y 13-392-3. 
que los consistorios de esta etapa dibujaron a la hora de preservar el ornato, el decoro y la higiene en el espacio. En ese escenario destacaron las comisiones de concejales que se crearon para dirigir visitas a barrios extremos de la ciudad ${ }^{56}$ y la forma en la que cooperaron con la Junta Municipal de Sanidad, los arquitectos del Ayuntamiento y los alcaldes de barrio a la hora de registrar los edificios cuyas condiciones exteriores e interiores perjudicaran al paisaje urbano ${ }^{57}$. De igual manera, la preservación de la seguridad poblacional también se condicionó a la necesidad de una mayor fiscalización sobre los establecimientos industriales peligrosos, y de manera concreta, sobre los que actuaban como depósitos de materias inflamables (petróleo, aceite mineral y gas mille), por los incendios que ocasionalmente provocaban $^{58}$. Es cierto que la eficiencia de estas iniciativas debe ponerse en tela de

${ }^{56}$ AVM-S, Nombramiento de comisiones para girar visitas a los barrios extremos de Madrid que tomen nota de los edificios que por su clase y condiciones perjudiquen al ornato y a la higiene, 19 de octubre de 1868, sig. 5-498-9.

57 En los registros se enumeraban las casas en estado de abandono, las ruinosas, las que no se hallaban en las alineaciones oficialmente fijadas para las calles en las que se ubicaban, las que precisaban revoco de sus fachadas, las que evidenciaban hacinamiento, las que ofrecían condiciones insuficientes para una correcta ventilación, las que no contaban con pozos negros, las que se hallaban rodeadas de basureros y las que no se atenían a lo acordado en las licencias de construcción. Los registros iban acompañados de la apertura de expedientes, en los que se fijaban los procedimientos que debían seguir los propietarios de las casas denunciadas para ejecutar su derribo con carácter inmediato, su reforma o su reedificación. Muchos de estos expedientes quedaron paralizados, al alegar los caseros falta de medios económicos para su cumplimiento. En tales condiciones, la mayor parte de las actuaciones que se realizaron en el plano de mejoras residenciales se centraron en operaciones de revoco de fachadas exteriores. Véanse: AVM-S, Comunicaciones de policía urbana. Tenencia de alcaldía del distrito de Hospicio. Reconocimiento de viviendas del visitador general de policía urbana en el barrio de Chamberí, 22 de marzo de 1869, sig. 13-378-2; AVM-S, Comunicaciones de policía urbana. Tenencia de alcaldía del distrito de la Latina. Oficio sobre casas en mal estado y solares vacíos del visitador general de Policía Urbana, 23 de febrero de 1869, sig. 14-21-2: AVM-S, Comunicaciones del Ayuntamiento de Madrid. Tenencias de alcaldía de los distritos de Hospicio y la Latina. Informes sobre casas en mal estado, 23 de febrero de 1870, sigs. 13-392-2 y 14-21-5; AVM-S, Documentación de policía urbana. Tenencia de alcaldía del distrito de Centro. Partes donde se informa del estado ruinoso o deteriorado de varias casas, 1870, sig. 13-221 y AVM-S, Documentación de policía urbana. Tenencia de alcaldía del distrito de Hospicio. Expedientes de edificios ruinosos, 1872, sig. 13392-3.

58 Desde comienzos del Sexenio, tanto la prensa como el vecindario solicitaron al consistorio el desplazamiento de estos establecimientos a espacios alejados de los principales núcleos poblacionales y una mayor vigilancia sobre las condiciones en que operaban. Estas reivindicaciones llevaron a la aprobación de disposiciones que incidieron en dos aspectos. El primero aludía a las condiciones que debían prevalecer en el almacenaje de combustible dentro de los locales de venta al por menor, relativos a la fijación de límites en número de litros para el petróleo y el gas mille, a normas de conservación y transporte y a reglas de separación con respecto a estancias habituales de personas y lugares de 
juicio, valorando las numerosas referencias que se hicieron con respecto a su incumplimiento. En la mayoría de los casos, su ejecución se vio condicionada por las dificultades económicas del municipio. Pero no por ello debe obviarse el objetivo de crear una nueva "gramática» sobre el espacio urbano (Lousada, 2005), a la hora de reformar, resignificar y modernizar la gestión de los servicios concernientes a la policía urbana. Los debates que se pusieron sobre la mesa fueron novedosos en ciertos apartados y revelaron cambios con respecto a la forma de reflexionar sobre una ciudad en transformación.

\section{EL DESPLIEGUE DE LAS PRÁCTICAS DE PROFILAXIS Y CONTROL SOCIAL EN LA CIUDAD EN EL SEXENIO DEMOCRÁTICO}

Los gobiernos municipales del Madrid del Sexenio no solo tomaron conciencia con respecto a la necesidad de mejorar las condiciones de ornato, higiene y salubridad de la ciudad sobre la base de iniciativas que reforzaran los mecanismos de gestión de la policía urbana. De manera paralela, sus propuestas de incrementar su grado de intervención en la ciudad respondieron a premisas nacidas en el seno de sus propias líneas de actuación o provenientes de las definidas por el Gobierno Civil de la provincia de Madrid. A través de unas y otras, se buscaban establecer unos mecanismos de control más rigurosos sobre conductas asociadas no ya al orden de la ciudad en términos de planificación, funcionalidad y estructuración, sino a la concepción de aquella como cuerpo social ${ }^{59}$. Podía preocupar la limpieza de las calles, los marcos de seguridad en que operaban los establecimientos industriales y las garantías proporcionadas a la población en el consumo de alimentos, pero también inquietaba la gestión de las actitudes colectivas e individuales en un espacio público que, en lo que respecta al plano de las costumbres cívicas y morales, se entendió como caótico, confuso y desordenado.

La preservación del orden público y el control social jugaron un papel fundamental en la retórica del poder local y provincial de Madrid desde los primeros

paso frecuente de la población. El segundo aspecto determinaba dos normas esenciales: prohibición de la venta de petróleo y gas mille por la noche y ubicación de los depósitos al por mayor en las afueras y a una distancia de más de veinte metros con respecto a cualquier edificio habitado. Véanse: AVM-S, Circular a los alcaldes de barrio para que se sirvan dar las órdenes oportunas a fin de que por los dependientes de su autoridad se vigile escrupulosa y constantemente el establecimiento de depósitos de petróleo y gas mille sin la licencia necesaria y precisa, 5 de mayo de 1869, sig. 5-394-34; AVM-S, Circular de la alcaldía sobre depósitos de aceite mineral en Madrid, 1 de agosto de 1870, sig. 14-21-5 y AVM-S, Varias disposiciones sobre venta de petróleo y aceite mineral, 26 de junio de 1872, sig. 13-222-2.

59 Sobre la noción de control social y su aplicación al ámbito europeo en el siglo XIX, véanse las reflexiones compiladas en: Emsley, Johnson y Spierenburg, 2014. 
compases del Sexenio. Tales objetivos ya se hicieron palpables en las actuaciones de las juntas revolucionarias, que velaron por la tranquilidad ciudadana y el respeto a la propiedad privada a nivel de distrito y barrio. En última instancia, se buscó una transferencia pacífica de poderes, tarea que quedó en manos de alcaldes de barrio elegidos en función de su compromiso político y de una milicia civil organizada en retenes. La actuación de esta última, conocida bajo el nombre de Voluntarios de la Libertad, fue crucial para evitar manifestaciones populares que no fueran pacíficas, salvaguardar los edificios más representativos y desarmar a quienes, sin quedar bajo el control de las juntas, recorrían los barrios "haciendo disparos» y provocando «inquietud en las familias que, encerradas en sus casas, ignoraban la causa y efectos de los mismos» ${ }^{60}$.

De la Fuente ha explicado la transferencia pacífica del poder político para Madrid sin negar el alto nivel de intimidación que podía observarse en las calles tras los sucesos revolucionarios, visible en los gritos proferidos contra la monarquía recién derrocada y en la eliminación de símbolos relacionado con aquella en el espacio urbano (De la Fuente, 2000, pp. 74-83). Sin embargo, no hay que olvidar que a esas expresiones de intimidación inicial siguieron lo que el Ayuntamiento de Madrid definió como "abusos» y "desórdenes» sociales motivados por las «extraordinarias circunstancias» que atravesaba la ciudad ${ }^{61}$. Unos abusos y desórdenes que llevaron a fijar una serie de normas para practicar registros domiciliarios, ocupar locales, identificar a personas no documentadas y capturar a quienes amenazaran la seguridad pública ${ }^{62}$.

La aplicación del orden público y del control social en el Madrid del Sexenio concernió a temáticas diversas. Unas eran ampliamente conocidas, otras resultaron deudoras del contexto político, social y económico de esos años y las últimas fueron producto de las dinámicas expansivas advertidas en una ciudad que oponía obstáculos a la fiscalización de comportamientos sociales conceptualizados como «desviados» en determinados espacios liminares. No sorprende que la represión de la mendicidad callejera tuviera un protagonismo innegable a lo largo de todo el período. Sin embargo, su análisis adquiere relevancia si se tiene en cuenta la forma en la que se reforzaron los propósitos de exorcizarla, especialmente en las fases en las que adquirieron mayor resonancia el paro y la crisis laboral. Como ya se ha demostrado para otros puntos del país (Serrano, 1986; Giménez Muñoz, 2006, pp. 83-95), la prensa no escatimó en alusiones a este problema social y a la for-

60 La Correspondencia de España, 30 de septiembre de 1868.

61 AVM-S, Bando de la alcaldía de Madrid sobre buen gobierno, 5 de noviembre de 1868, sig. 4-406-23.

62 AVM-S, Circular de la alcaldía de Madrid a las tenencias de alcaldía de distrito para extremar la rigurosidad en las actuaciones de los alcaldes de barrio, 29 de octubre de 1868, sig. 13-391-1. 
ma en la que iba adquiriendo proporciones sistemáticamente categorizadas como "alarmantes» ${ }^{63}$. Todo ello vino acompañado por consideraciones que, enfatizando las virtudes éticas del trabajo y las implicaciones morales de la vagancia, estipulaban la nula permisividad a seguir con quienes invadían el espacio público exhibiendo «lacras y andrajos», produciendo «constantes molestias y repugnancias» a los viandantes y «corrompiéndose y desmoralizándose» hasta dedicarse a «los más abyectos vicios y crímenes» ${ }^{64}$.

Las principales actuaciones en el capítulo de mendicidad vinieron del Gobierno Civil de la provincia de Madrid. A finales de octubre de 1868 su máxima autoridad, José Moreno Benítez, publicó un primer bando mediante el que disponía la prohibición de pedir limosna en las vías públicas y la circunscripción exclusiva de licencias para implorar la caridad a personas "verdaderamente imposibilitadas» para dedicarse al trabajo, faltas de recursos económicos o sometidas a la necesidad de pedir para atender a su subsistencia y a la de sus familias por circunstancias «independientes de su voluntad ${ }^{65}$. Como era común en otros contextos de conflictividad social y económica, esas excepciones se aplicaban a los nacidos en Madrid. La contravención de estas normas daba cabida a tres posibles escenarios. Primero, el traslado al Asilo de San Bernardino de quienes hubieran sido interceptados mendigando sin licencia, siempre que fueran naturales de Madrid. Segundo, el traslado a sus pueblos de procedencia de los que, aprehendidos en la misma situación que los anteriores, fueran inmigrantes. Y tercero, el envío a juzgados de primera instancia de aquellos que reincidieran en el ejercicio de la mendicidad tras una detención previa. No eran medidas novedosas. En verdad, reproducían la retórica de los bandos de la etapa isabelina, mantenidos en idéntica línea en los primeros años de la Restauración (Bahamonde y Toro, 1978b; Sánchez Ceballos, 2015 y De Miguel, 2017c).

Meses después, el 17 de junio de 1869, un segundo bando reforzaba las disposiciones del anterior, prohibiendo la limosna en las calles de Madrid y en las afueras y ordenando la nulidad de las licencias que hasta entonces se hubieran concedido para tal objeto por el Ayuntamiento. El motivo que vehiculaba este nuevo mandato era la medida que acababa de materializarse en el sistema asistencial de la ciudad: la apertura del asilo de mendicidad de San Juan en la locali-

${ }^{63}$ Véanse también las páginas que a la cuestión de la pobreza en este período se dedican en: Maza, 1999.

64 Todas estas apreciaciones permean la mayoría de las crónicas que los periódicos del Sexenio dedicaron al problema de la mendicidad. En: La Iberia, 27 de enero, 18 de febrero y 8 de octubre de 1872; El Imparcial, 22 de febrero y 22 de septiembre de 1872; La Nación, 27 de abril y 12 de julio de 1871; 30 de marzo y 9 de mayo de 1872; La Época, 11 de abril de 1869, 7 de agosto de 1871 y 22 de septiembre de 1872 y La Correspondencia de España, 24 de septiembre de 1872 y 23 de enero de 1873.

65 La Correspondencia de España, 28 de octubre de 1868. 
dad de El Pardo. Su creación, inspirada por criterios filantrópicos y sostenida por suscripciones públicas, respondió al objeto de mejorar el estado de la Beneficencia y a la necesidad de incrementar las infraestructuras disponibles para abordar el internamiento de mendigos, en aquel momento prácticamente circunscritas al Asilo de San Bernardino, inaugurado en 1834 y caracterizado por una funcionalidad que engarzaba con la represión de «todos aquellos marginados que estorbaban a la sociedad" y con su apartamiento de las vías públicas (Vidal Galache, 1992). Como señalaba La Iberia, el proyecto de Moreno Benítez iba acompañado por el propósito de establecer un segundo asilo en Aranjuez, en el que se abriera un establecimiento agrícola e industrial donde encontraran educación, trabajo y porvenir «los muchachos de doce a dieciséis años que tanto en esta capital como en su provincia hacen la vida de vagos, perturbando todos los sitios públicos, adquiriendo vicios y caminando a las funestas consecuencias de una existencia que solo conduce a los crímenes» ${ }^{66}$.

En el momento de su inauguración, el Asilo de San Juan contaba con capacidad para ochocientos mendigos (varones de más de siete años y ancianos imposibilitados), objeto de una reeducación trazada desde la disciplina laboral desarrollada en talleres de zapatería, carpintería, herrería y sastrería. En lo que respecta al Asilo de Aranjuez, su proyección varió su emplazamiento original para ubicarse junto al de San Juan. Se trataba del Asilo de Santa María, abierto a finales de 1869 y con capacidad para cuatrocientos acogidos (mujeres indigentes de todas las edades y niños menores de siete años). La definitiva instalación de este último en El Pardo respondió a las ventajas de inspección y economía que esperaban obtenerse de la proximidad de los dos espacios ${ }^{67}$. La organización de los dos asilos expresaba criterios unívocos, que remitían al carácter voluntario o forzado de los ingresos, al pensamiento de que el vecindario de Madrid no debía sostener a mendigos de otras provincias (exceptuando a ancianos, incapacitados físicos, niños de muy corta edad y personas con largo tiempo de residencia en la ciudad sin familia reconocida) y a reglas de permanencia en función de la edad (tres meses y tres años para mayores y menores de edad respectivamente) ${ }^{68}$.

${ }^{66}$ La Iberia, 14 de mayo de 1869.

67 La Nación, 4 de febrero de 1870.

${ }^{68}$ Reglamento para los Asilos de Mendicidad de San Juan y Santa María establecidos en El Pardo, Madrid, Oficina Tipográfica del Hospicio, 1871. 
Tabla 1. Acogidos por los Asilos de San Juan y Santa María, con expresión de lo gastado por subsistencias (junio de 1869 a septiembre de 1871 ) ( $^{69}$

\begin{tabular}{|c|c|c|}
\hline 1869 & Número de acogidos & Gastos por subsistencias (reales) \\
\hline 24 al 30 de junio & 383 & 112 \\
\hline Julio & 729 & $22.087,48$ \\
\hline Agosto & 693 & $10.258,37$ \\
\hline Septiembre & 767 & $33.206,03$ \\
\hline Octubre & 761 & $30.893,48$ \\
\hline Noviembre & 787 & $22.606,45$ \\
\hline Diciembre & 830 & $13.426,09$ \\
\hline Total 1869 (junio-diciembre) & 4.950 & $132.589,90$ \\
\hline 1870 & Número de acogidos & Gastos por subsistencias (reales) \\
\hline Enero & 872 & $39.168,20$ \\
\hline Febrero & 765 & $43.033,26$ \\
\hline Marzo & 724 & $29.238,18$ \\
\hline Abril & 725 & $44.375,55$ \\
\hline Mayo & 745 & $37.150,43$ \\
\hline Junio & 712 & $21.879,98$ \\
\hline Julio & 818 & $29.134,02$ \\
\hline Agosto & 807 & $49.637,74$ \\
\hline Septiembre & 848 & $62.240,97$ \\
\hline Octubre & 907 & $38.519,31$ \\
\hline Noviembre & 766 & $38.859,66$ \\
\hline Diciembre & 752 & $34.944,78$ \\
\hline Total 1870 & 9.501 & $468.182,08$ \\
\hline 1871 & Número de acogidos & Gastos por subsistencias (reales) \\
\hline Enero & 825 & $49.910,99$ \\
\hline Febrero & 819 & $33.415,28$ \\
\hline Marzo & 711 & $36.937,75$ \\
\hline Abril & 693 & $43.524,79$ \\
\hline Mayo & 663 & $36.843,21$ \\
\hline Junio & 613 & $34.931,70$ \\
\hline Julio & 629 & $29.086,99$ \\
\hline Agosto & 597 & $31.214,88$ \\
\hline Septiembre & 562 & $27.455,57$ \\
\hline Total 1871 (hasta septiembre) & 6.112 & $323.321,16$ \\
\hline
\end{tabular}

Fuente: Asilos Benéficos de El Pardo. Estados de ingresos y gastos desde el 25 de mayo de 1869 a fin de septiembre de 1871, Madrid, s. e., 1871.

69 Presentándose en esta tabla el desglose de acogidos por meses, queda significar su distribución por sexo: 2.256 hombres, 1.081 mujeres, 986 niños y 627 niñas del 24 de junio al 31 de diciembre de 1869; 4.108 hombres, 1.933 mujeres, 2.400 niños y 1.060 niñas en 1870 y 2.369 hombres, 1.137 mujeres, 1.965 niños y 641 niñas de enero a septiembre de 1871. 
Como había ocurrido tres décadas antes, en el marco de la creación del Asilo de San Bernardino, la inauguración de los Asilos de El Pardo dio pie a una intensificación de las redadas para recoger a los mendigos de las calles de Madrid $^{70}$, en un intento inequívoco de inocular, al igual que en otras ciudades europeas, una profilaxis social sobre el espacio público (Lawrence, 2004, pp. 210-225). A principios de febrero de 1870, Moreno Benítez, dio cumplido testigo de la solvencia con la que cumplían ese cometido los agentes de orden público dependientes de su autoridad. Esas operaciones afectaban a veinticinco indigentes diarios por término medio y solo en diciembre de 1869 a 735, de los que 212 fueron enviados a EI Pardo, quedando 73 en libertad. Los 450 restantes eran inmigrantes que debían ser transportados a sus pueblos de procedencia, mediante tránsitos realizados por la Guardia Civil ${ }^{71}$.

Si la valoración que Moreno Benítez hacía con respecto a su objetivo de avanzar hacia la extinción de la mendicidad era positiva en los anteriores conceptos, no se desprendía la misma sensación de las circulares que envió a los alcaldes de barrio y a los tenientes de alcalde de los distritos de Madrid. Las peticiones que remitió a esas instancias incidieron en la aprehensión de aquellos mendigos que evadían las disposiciones prohibitivas comentadas, en la detección de los "falsos pobres» o «no menesterosos» y en la interrupción absoluta de las concesiones de licencias para implorar la caridad pública. De manera paralela, sobresalían las instancias que encomendaban una mayor vigilancia de los espacios en los que habitualmente se ejercía la mendicidad (pórticos de iglesias, esquinas de las calles más céntricas), de los lugares que los indigentes frecuentaban con carácter nocturno para idéntico fin que el anterior (puertas de teatros, cafés, tabernas) y de los enclaves que les servían de alojamiento (bancos del Museo de Prado, verjas del Jardín Botánico, portales de viviendas particulares, solares, cuevas subterráneas, etc) $)^{72}$. Para todo ello, se requería la constante cooperación entre los guardias de policía urbana, dependientes del Ayuntamiento de Madrid, y los agentes de orden público, bajo mandato del Gobierno Civil, especialmente en lo que respecta a la recogida de mendigos inmigrantes ${ }^{73}$. Era precisamente en este punto donde se producían los mayores conflictos entre la autoridad provincial y la municipal, como se deduce de la comunicación enviada por Moreno Benítez a la alcaldía de Madrid el 21 de septiembre de 1869:

70 Sobre las recogidas de mendigos en el Madrid de este período, véase: Llano, 2018, pp. 173-176.

${ }^{71}$ La Nación, 4 de febrero de 1870.

72 Los «espacios de la mendicidad» en el Madrid de esta etapa en: Vega-Rey, 1885, pp. 32-44.

${ }^{73}$ AVM-S, Circular del gobernador civil de la provincia de Madrid a Simón Pérez, teniente de alcalde del distrito de Centro, 4 de agosto de 1869, sig. 13-220-2. 
Grandes sacrificios, obstáculos de importancia, he tenido que remover para el establecimiento del asilo benéfico de El Pardo, y estos sacrificios sólo han conocido por causa hacer que desapareciera de una manera total ese cúmulo de mendicidad que invadía las calles de la población, dando un espectáculo triste, repugnante y contrario a los adelantos de la civilización moderna. Bajo este concepto, me propuse hacer frente a las necesidades de los que perteneciendo a la provincia de Madrid, se hallaran en el caso de ser atendidos, haciendo salir para los pueblos de su naturaleza a cuantos sin medios conocidos de subsistencia imploraban la caridad pública. Pero esta medida, secundada de manera satisfactoria por los agentes de orden público, ha sido desatendida de un modo manifiesto y censurable por los guardias municipales dependientes del Ayuntamiento de Madrid (...). Esta falta de cumplimiento y esta apatía a órdenes superiores por parte de dichos empleados ha resaltado más y más en estos últimos días, en que han invadido de nuevo las calles de la capital una multitud de pobres de varias edades, teniéndose que adoptar en el día de ayer medidas enérgicas para recogerlos, dando por resultado la detención de un número considerable de aquellos que no pertenecen a la provincia de mi mando ${ }^{74}$.

El objetivo de reprimir la mendicidad callejera se desarrolló en un plano paralelo al de limitar la prostitución en las vías públicas de Madrid. Ya en una comunicación dirigida a la alcaldía de la capital española el 12 de noviembre de 1868, Moreno Benítez expresaba su inquietud con respecto a la forma en que aquella actividad se ejercía «a la sombra de la seguridad individual» y con «cínicos alardes» en las calles más transitadas. En las líneas de actuación de la autoridad gubernativa provincial, la prostitución merecía, a su juicio, la misma atención preferencial que la mendicidad y que el juego, que se analizará posteriormente. En consecuencia, se anunciaban medidas para disminuir lo que se definía como un «lunar social» ruidosamente ostentado en el espacio público ${ }^{75}$.

Como ya ha explicado Guereña, el Sexenio fue una etapa en la que se consolidó el reglamentarismo sobre la actividad prostitucional del contexto isabelino. Ahora bien, la coyuntura abierta tras la Revolución marcó una nueva era en el anterior escenario, por la relevancia que cobró la noción de la higiene especial aplicada a servicios administrativos, médicos y policiales responsabilizados del control y la vigilancia de la prostitución en tres apartados (fiscalización de la actividad mediante inscripciones administrativas; controles sanitarios a partir de los registros realizados por higienistas facultativos y sanciones económicas si se verificaba la contravención de las normas fijadas por la autoridad gubernativa) (Guereña, 2003, pp. 245-260).

74 AVM-S, Comunicación de la alcaldía de Madrid a los tenientes de alcalde de los distritos municipales, expresando órdenes sobre extinción de la mendicidad, 16 de septiembre de 1869, sig. 13-391-2.

${ }^{75}$ AVM-S, Comunicación del gobernador civil de la provincia de Madrid al alcalde de Madrid, 12 de noviembre de 1868, sig. 13-391-1. 
En el caso de Madrid, esa noción de higiene especial se oficializó con la creación de un reglamento aprobado por Moreno Benítez el 1 de mayo de 1869 y puesto en vigor un mes más tarde ${ }^{76}$.

Siguiendo nuevamente a Guereña, el Reglamento de Higiene Especial de 1869 quedaba vehiculado por un planteamiento liberal (Guereña, 2003, pp. 250-252). Las principales responsabilidades recaían sobre las amas de las casas de lenocinio, en los casos en los que estas últimas se dedicaran a la actividad sin proveerse de licencias y sin abonar cuotas o llevar al día los registros de sus pupilas. Al mismo tiempo, eran aquellas las que corrían con el grueso de las multas que podían imponerse por los escándalos o las conductas deshonestas verificadas por sus huéspedes. Asimismo, y a diferencia de lo que se había prescrito con anterioridad, las pupilas podían "transitar libremente por los sitios públicos», aunque siempre sujetándose a las «leyes de la moral y del decoro» ${ }^{77}$.

Pese a su tono liberal, el Reglamento de Higiene Especial fue objeto de críticas reseñables. Dejando a un lado aquellas que desde la prensa establecieron una conexión entre tolerancia de la prostitución y fomento y protección de la misma ${ }^{78}$, una de las más incisivas fue la publicada por el Doctor Machucho en El Eco de las Ciencias Médicas. A juicio del especialista, la organización que se dio al cuerpo de higienistas facultativos (diez médicos) no era lo suficientemente completa como para obtener los resultados que se esperaban desde el Gobierno Civil. Las visitas domiciliarias a las casas de lenocinio no se practicaban con regularidad y con minuciosidad, lo que dejaba a aquellas en una situación de cierto abandono que tenía su correlato en un notable incremento de los casos de sífilis. Siendo cauto con la objetividad de estas apreciaciones, interesa la manera en la que el señalado doctor contrastaba la tolerancia establecida para las casas de lenocinio con la forma en la que crecía la presencia de prostitutas en las vías públicas ${ }^{79}$. La documentación municipal aporta, nuevamente, indicios significativos en ese escenario.

Siguiendo las directrices del Reglamento de Higiene Especial, los alcaldes de barrio desempeñaban actuaciones orientadas a evitar los escándalos ocasionados en las proximidades de las casas de lenocinio toleradas en la ciudad, en conjunción con los guardias de policía urbana del Ayuntamiento y el cuerpo de orden público dependiente del Gobierno Civil. En la mayoría de los casos, la información que aquellos recibían venía determinada por denuncias previas del vecindario, que habitualmente exigía la intervención de las autoridades para reprimir con severidad los ruidos que las mujeres daban «aún en las altas horas de la mayor parte de las

${ }^{76}$ Reglamento de Higiene Especial. 1869, Madrid, Imprenta de J. M. Ducazcal, 1869.

77 Artículo 20 del reglamento. En: Reglamento de Higiene Especial..., op. cit., p. 7.

78 La Igualdad, 11 de abril de 1871.

79 MACHUCHO, Dr.: «La prostitución en Madrid», en El Eco de las Ciencias Médicas, n.ㅇ 25, 23 de junio de 1870, pp. 385-386. 
noches» y las actitudes que mostraban atentando "contra la moral pública»" En relación con este punto, los alcaldes de barrio controlaban los comportamientos que las prostitutas mostraban en las puertas y balcones de las casas en las que se hallaban inscritas como pupilas (produciendo «un mal ejemplo a los honrados que transitan por la calle», como señaló el alcalde del barrio de Cruz $)^{81}$ y en los espacios de sociabilidad popular, entre los que descollaban las tabernas.

Dentro del anterior escenario resulta ejemplificadora la carta remitida por el alcalde del barrio de Aguas, Francisco Fernández, al teniente de alcalde del distrito de la Latina en 1869, con el fin de que este último la transmitiera a continuación al gobernador civil de la provincia. Francisco Fernández iniciaba su misiva aludiendo a las numerosas quejas que venía recibiendo como consecuencia de los «continuos escándalos promovidos por las mujeres mundanas» que concurrían en varias tabernas de la calle del Rosario. Refería la escasa efectividad que habían tenido las numerosas advertencias hechas a aquellas mujeres y las medidas que sistemáticamente tomaban tanto los integrantes del cuerpo de policía urbana como las fuerzas del orden público. Unas y otras habían actuado en diferentes ocasiones con motivo de la "mala compostura de aquellas» y de las palabras «obscenas y desvergonzadas» que pronunciaban en mitad de la vía pública. Sin embargo, la comunicación en cuestión respondía a lo que la autoridad local había presenciado en la parte exterior de una de las tabernas existentes en aquella zona. En la acera situada frente al número 3 de la citada calle del Rosario (donde se enclavaba el despacho de vinos), Francisco Fernández había presenciado cómo una de las huéspedes de la casa de lenocinio más próxima se encontraba con un hombre "en el ademán más escandaloso» y pronunciando "cantares sumamente obscenos». Como era habitual en este tipo de ocasiones, se procedió a sancionar económicamente a la dueña de la casa tolerada, en la que caía la responsabilidad principal, con una multa de cincuenta escudos ${ }^{82}$.

El control de la mendicidad y la prostitución en la vía pública conectaba con otro objetivo que podría tipificarse como el tercer pilar de la profilaxis social a implementar en el medio urbano: la vigilancia y la represión de las conductas ilícitas intensificadas durante el Sexenio principalmente asociadas a la práctica de los llamados "juegos prohibidos» (de suerte, de envite, de azar), ya tuvieran lugar en el espacio público, ya se desarrollaran en espacios de sociabilidad popular o habili-

${ }^{80}$ AVM-S, Documentación de policía urbana. Tenencia de alcaldía del distrito de Congreso. Denuncias de casas de prostitución por los alcaldes de los barrios de Lobo e Izquierdo, 1869, sig. 12-352-1.

${ }^{81}$ AVM-S, Documentación de la tenencia de alcaldía del distrito de Congreso. Denuncias de la casa de prostitución de la calle del Pozo n.o 6 por el alcalde del barrio de Cruz, 1869, sig. 12-352-1.

82 AVM-S, Comunicaciones de policía urbana. Tenencia de alcaldía del distrito de la Latina. Circular del alcalde del barrio de Aguas sobre prostitución en la calle del Rosario n.․․ 3, 1869, sig. 14-20-7. 
tados de manera clandestina en edificios de vecindad. Pino Abad ha explicado el encendido debate social y político que en torno a la anterior cuestión se abrió en el siglo XIX, en el que fueron partícipes tanto aquellos que podrían definirse como detractores del juego (entendido no como recreación, sino como elemento a perseguir por las consecuencias perniciosas que podía traer a nivel individual, por la manera en la que comprometía la supervivencia económica familiar y por la forma en que contribuía a la relajación y perversión de las costumbres) y aquellos que se apartaban de esa línea de confrontación para reconocer el derecho que amparaba al individuo de cara a apostar parte de sus bienes patrimoniales, siempre que con ello no repercutiera negativamente en intereses de terceros o incurriera en fraude (Pino Abad, 2011, pp. 25-28). En el Madrid del Sexenio tomó preponderancia la primera de esas dos caras del debate, advertida desde el momento en el que el Gobierno Civil expresó su preocupación con respecto a la intensidad que el juego venía cobrando en ciertos espacios urbanos. Un juego que, a deducir de la siguiente alocución de Moreno Benítez (la misma en la que se consignaba a la alcaldía de Madrid el incremento observado por la prostitución en las vías públicas), se consideraba como una actividad apartada de lo que debía concebirse como una «recreación racional» (Bailey, 1978), que amenazaba virtudes como el afán en el desempeño laboral, el ahorro y la abnegación y que resultaba en la ruina a nivel individual y familiar, principalmente en el seno de las capas populares ${ }^{83}$ :

Los principios que la Revolución proclamó desde sus albores y que el Gobierno Provisional respeta escrupulosamente han llevado la libertad a todas las esferas, permitiendo que la iniciativa individual se abra paso por todas partes y recorra sin obstáculos todos los caminos. Ese cambio profundo y anhelado produce en el país el fecundo movimiento que todos contemplamos y facilita, en gran manera, el desarrollo de su actividad y de su riqueza, pero sirve a la vez de pretexto para que el vicio se extienda y para que puedan multiplicarse los atentados contra la moral que turban la paz del hogar doméstico (...). Explotando el respeto que el domicilio merece y obtiene ahora, se multiplican las casas de juego, donde los padres van a dejar el pan de los hijos y donde los hijos menores de edad en muchos casos defraudan lastimosamente las esperanzas de sus familias y corresponden al afán de los padres, abrazando con ceguedad el más trascendental de los vicios.

Al igual que ocurría con la mendicidad y la prostitución, el Gobierno Civil entendía como indispensable la aplicación de medidas que atacasen las nuevamente categorizadas como «alarmantes proporciones» que los juegos prohibidos iban tomando en la ciudad ${ }^{84}$, sirviéndose para ello no solo de los agentes de orden público

${ }^{83}$ Sobre las preocupaciones que entre las autoridades europeas generaron el juego y las apuestas en el espacio público, véanse: Munting, 1996, pp. 6-31 y Clapson, 1992, pp. 14-78.

84 La naturaleza de los juegos prohibidos (envite, azar y suerte) como actividad social 
dependientes de su autoridad, sino también del auxilio de los alcaldes de barrio, precisamente por el grado de conocimiento que estos últimos tenían con respecto al vecindario y sus prácticas sociales cotidianas. A todo ello se instaba en beneficio de la moral, la conducta pública, la prevención de la violencia física y el crimen, la necesaria extinción de los focos de corrupción diseminados en el tejido urbano y la defensa de las personas clasificadas como «incautas», manejadas por quienes se tipificaban como «vagos» o "gentes sin oficio» ${ }^{85}$.

Dos fueron los escenarios en los que se combatieron los juegos de suerte, envite y azar durante el Sexenio en Madrid. El primero de ellos concernió a las ya referidas casas de juego, fundamentalmente situadas en los barrios del centro. Tanto el Gobierno Civil como el Ayuntamiento de Madrid emitieron disposiciones con respecto a las mismas, de cara a clausurar las dedicadas a los mencionados juegos prohibidos $^{86}$. A esas órdenes acompañaron otras que incidieron en la supresión de los juegos de ruleta para la rifa de juguetes y otros artículos ${ }^{87}$, en la persecución de los juegos de lotería en establecimientos desprovistos de autorización municipal para tal objeto y en la imposición de horas de cierre para los espacios de sociabilidad popular en los que clandestinamente se desarrollaban actividades lúdicas ilícitas ${ }^{88}$. Una normativa que generó protestas entre los dos sectores afectados, esto es, los dueños de cafés y los dueños de tabernas y despachos de vinos, a los que se fijaron límites de cierre a las dos de la mañana y a las doce de la noche respectivamente ${ }^{89}$.

delictiva quedó estipulada en el Código Penal de 1848. La legislación del Sexenio, verificada en el Código Penal de 1870, no planteó cambios de relevancia en la anterior normativa, fijando los castigos a imponer sobre los dueños de las casas de juego (penas de arresto mayor y multas de entre 250 y 2.500 pesetas). En: Pino Abad, 2011, pp. 125-140.

85 La Correspondencia de España, 25 de octubre de 1868; La Época, 11 de noviembre de 1868; La Discusión, 27 de noviembre de 1868; El Imparcial, 13 de abril de 1869 y La Igualdad, 20 de julio de 1869.

${ }^{86}$ El Imparcial, 12 de abril de 1871.

87 AVM-S, Actas de juntas de los tenientes de alcalde de Madrid, 30 de noviembre de 1870 y 16 de octubre de 1871, sig. 18-254-6 y AVM-S, Comunicaciones del Ayuntamiento de Madrid. Circular sobre juegos prohibidos y prohibición del juego de la ruleta, 19 de octubre de 1871, sig. 13-393-3.

${ }^{88}$ Muchas de estas iniciativas quedaron planteadas en las juntas de las tenencias de alcaldía y de las alcaldías de barrio de Madrid, como puede verse en: AVM-S, Actas de juntas de los tenientes de alcalde de Madrid, 22 de septiembre y 14 de octubre de 1869, sig. 18-254-6. La normativa relativa a las horas de cierre en: AVM-S, Circular del gobernador civil de la provincia de Madrid relativa a horas de cierre y juegos en tabernas y cafés, 18 de agosto de 1869, sig. 13391-2.

${ }^{89}$ Las quejas contra la disposición son mencionadas en: La Discusión, 4 de septiembre de 1869. Para un análisis de las posteriores interpretaciones de las tabernas como espacios amenazadores para el orden social en Madrid véase: Campos, 2001, pp. 43-56. 
Sin embargo, tanto de la prensa como de la documentación tramitada por el Ayuntamiento de Madrid se deduce una efectividad relativa en las anteriores actuaciones. Los principales obstáculos que se encontraron con respecto a la persecución y al cierre de las casas dedicadas a juegos prohibidos guardaban relación con las estrategias que sus dueños ponían en liza a la hora de evadir las disposiciones prohibitivas. En líneas generales, la más extendida consistía en trasladar las partidas de juegos de envite, azar y suerte a dependencias anexas a las propias casas de juego dentro de un mismo edificio de vecindad ${ }^{90}$. Una decisión que no era inocente. De esa forma, se proporcionaba carácter residencial al local donde se jugaba, lo que resultaba clave para burlar la vigilancia, especialmente si se tiene en cuenta el principio de inviolabilidad del domicilio de la Constitución de 1869 (Pascual, 2002) ${ }^{91}$. Este problema fue señalado en no pocas ocasiones tanto por los alcaldes de barrio como por los tenientes de alcalde, según se desprende de las juntas que ordinariamente celebraban estos últimos.

El segundo escenario de lucha contra los juegos prohibidos entroncó con el objetivo de controlar y supervisar todo lo que acontecía en las vías públicas. Si bien es cierto que el ejercicio del juego con fines ilícitos no se verificaba con regularidad en las calles del centro, sí reproducía patrones topográficos constantes en espacios que podrían entenderse como periféricos, liminares o heterotópicos. Espacios a medio camino entre la ciudad oficial surgida con el Ensanche y la no oficial extendida más allá de aquel, donde se hacían dificultosas la aplicación de normativas de seguridad, orden público y policía urbana provenientes del Gobierno Civil o del Ayuntamiento de Madrid, teniendo en cuenta que estaban escasa o nulamente provistos de guardias. Uno de ellos coincidía con la zona inmediatamente colindante a la Puerta de Bilbao o Puerta de los Pozos de la Nieve, que hizo las veces de cerca fiscal hasta su definitiva demolición con el triunfo de la Revolución. La tapia servía de bisagra entre los antiguos límites de la vieja ciudad y la nueva urbe que se abría con el proyecto del Ensanche, en su sección norte. Los vecinos del barrio al que administrativamente pertenecía ese enclave (Beneficencia) clamaron en diferentes ocasiones al Ayuntamiento por el abandono en que allí se encontraba la seguridad individual. En líneas generales, esa seguridad individual se veía amenazada por la proliferación que habían alcanzado los juegos prohibidos en la zona y, de manera particular, las apuestas desarrolladas en torno al juego de bolos ${ }^{92}$.

90 AVM-S, Actas de juntas de los tenientes de alcalde de Madrid, 14 de octubre de 1869, sig. 18-254-6.

${ }^{91}$ Ejemplos de la alegación de este principio por parte de los dueños de las casas de juego y de la necesidad de que los juzgados de primera instancia entendieran previamente en el asunto en: La Correspondencia de España, 27 de octubre de 1869 y La Época, 28 de octubre de 1869.

${ }_{92}$ AVM-S, Oficios de secretaría de la tenencia de alcaldía del distrito de Hospicio. Circulares de la alcaldía del barrio de Beneficencia sobre juegos prohibidos, 24 de enero, 23 de agosto, 17 y 29 de noviembre de 1869, 3 de enero de 1870, 20 de abril de 1871 y 4 de octubre de 1871, sigs. 
Para las autoridades locales, y en especial para la alcaldía del barrio de Beneficencia, ejercida por José Parrondo, lo preocupante de lo que acontecía en los Pozos de la Nieve no era solamente el hecho de que allí se practicara una actividad de ocio que, por estar enfocada a la obtención ilícita de ganancias económicas o la utilización de monedas falsas, resultaba moralmente reprobable. Además, inquietaba la forma en la que se compenetraba con otras actitudes que revelaban un relajamiento de lo que se concebía como una conducta individual apropiada. Actitudes sociales que, bajo su punto de vista, casaban con la holgazanería, la ociosidad y el mal vivir. A juicio de José Parrondo, el espacio donde solía ejercerse esa actividad lúdica servía como "albergue para malhechores», como enclave propicio para la venta de vino sin licencia y como zona de esparcimiento de jóvenes que practicaban la pedrea con el vecindario, con las vidrieras de las casas e incluso con los propios guardias de policía urbana cuando estos se personaban en la zona ${ }^{93}$. Actividades, todas ellas, que también se reproducían en algunos de los barrios que también acababan de anexionarse al término municipal de Madrid, como el de Peñuelas en el Ensanche Sur ${ }^{94}$, o en los entornos que antiguamente habían comunicado esa zona con el casco antiguo, como el portillo de Gil Imón. En este último espacio no eran las apuestas realizadas en los juegos de bolos, sino en el cané y en los juegos de monte, las que generaban preocupaciones. Así se deducía de las denuncias de Francisco Fernández, alcalde del barrio de Aguas, el 13 de marzo de 1869:

En el día de ayer, siguiendo el firme propósito de hacer desaparecer toda clase de juegos prohibidos que tan permanentes como perniciosos vienen siendo con perjuicio de la moral, de la conducta pública y de las personas incautas, me dirigí al sitio que los jugadores tienen destinado para teatro de sus fechorías, que es el denominado Campillo de Gil Imón, y sorprendí in fraganti a tres o cuatro corros bien concurridos donde se juega a las chapas, al cané y a las tres cartas, y considerado este no como juego, sino como estafa, porque en él a todos constantemente se les extrae el dinero y a veces hasta las prendas que llevan puestas, y sabiendo, como sé, que los individuos que a ello se dedican son los que tienen los peores antecedentes de cuantos allí concurren, apresé a cinco primero y otro después (...). Este último ha jurado, junto con otros tres compañeros en una taberna, que me han de asesinar cuando encuentren ocasión, por el solo delito de perseguirlos incesantemente. No pudieron ser más los presos porque iba acompañado solo de mi ordenanza, no siendo posible apoderarse de todos cuando apelan a la dispersión y fuga. Me consta además que no tienen oficio y que gastan con esplendidez sin conocérseles otra ocupación que la referida, no siendo escasas las

13-378-2, 13-391-2 y 13-392-2.

93 AVM-S, Documentación de policía urbana de la tenencia de alcaldía del distrito de Hospicio, Circular del alcalde del barrio de Beneficencia, José Parrondo, sobre inseguridad en los Pozos de la Nieve, 20 de abril de 1871, sig. 13-392-2.

${ }^{94}$ AVM-S, Actas de juntas de los tenientes de alcalde de Madrid, 13 de febrero de 1869, sig. 18-254-6. 
raterías que se lamentan a todas horas y que por los vecinos próximos se les atribuye ser los perpetradores. Es costumbre habitual en ellos andar embriagados, escandalizando al barrio, aporreando las puertas de las tabernas después de ser cerradas a las dos y tres de la madrugada, sin servir de nada mis continuas reprensiones y consejos ${ }^{95}$.

Francisco Fernández alegaba un problema crucial a la hora de enfrentarse a las disposiciones prohibitivas relacionadas con los juegos prohibidos y su práctica en las calles de Madrid: la insuficiente vigilancia de la que gozaban los espacios recién incorporados al término municipal, determinada por las características de un cuerpo de policía urbana que, aun habiéndose incrementado a principios de 1869, seguía siendo claramente incapaz de contener el orden social en enclaves liminares, y por la escasa armonización que aquel presentaba con respecto a los guardias de orden público sometidos a la autoridad del Gobierno Civil ${ }^{96}$. No era casual que aquella apreciación coincidiera con la del ya mencionado alcalde del barrio de Beneficencia José Parrondo, que a principios de 1870 se quejaba a la alcaldía de Madrid del hecho de verificar las rondas en aquella zona acompañado únicamente del guardia de policía urbana Ricardo Lapida desde las dos de la tarde hasta el anochecer, y todo ello en el mejor de los escenarios posibles, si se valora la forma en que mencionaba cómo él mismo y sus tres hijos debían constituirse frecuentemente en parejas de vigilancia para sostener la seguridad vecinal ${ }^{97}$. Juicios entre los que, en definitiva, existían paralelismos, engarzando, a su vez, con los provenientes de las alcaldías de barrios del Ensanche muy superiores en términos poblacionales y de extensión a los del casco antiguo, como el de Chamberí. Así lo atestiguaba Simón Lerroux, al informar a la alcaldía de los problemas que contemplaba al controlar aquella zona:

Habiéndome hecho cargo de la alcaldía de este barrio y queriendo dar cumplimiento a tan honroso cometido de una manera en cuanto de mí dependa que nada deje de desear, debo poner en conocimiento de V.S. lo que desde luego creo necesario. Este barrio tiene más de ocho mil almas, o sea, el duplo con exceso que cualquiera de los mayores de Madrid, y la asignación que para gastos de personal y oficina hay destinada es tan excesivamente pequeña que el público tiene que estar necesariamente más servido. También debo llamar la atención de V. S. de que desde que se suprimió el cuerpo de guardia compuesto por los Voluntarios de la Libertad, solo se han destinado a este barrio tres individuos del orden público y tres guardias municipales, los cuales,

95 AVM-S, Comunicaciones del Ayuntamiento de Madrid. Distrito de la Latina. Denuncia de juegos prohibidos de la alcaldía del barrio de Aguas, 13 de marzo de 1869, sig. 14-20-9.

${ }_{96}$ AVM-S, Actas de juntas de los tenientes de alcalde de Madrid, 2 y 20 de diciembre de 1869, sig. 18-254-6.

97 AVM-S, Documentación de policía urbana. Tenencia de alcaldía del distrito de Hospicio. Circular del alcalde del barrio de Beneficencia a la alcaldía de Madrid, 3 de enero de 1870, sig. 13-392-2. 
además, tienen, al parecer, otras atenciones que cubrir, resultando que la mayor parte del tiempo está este barrio sin fuerza, cuando es mucho más necesaria que en otros por su extensión, número de habitantes y por la afluencia en días festivos de la población del interior ${ }^{98}$.

Como se observa en los casos precedentes, la mejora de la gobernabilidad que se buscaba para el espacio urbano por las autoridades chocaba con las crecientes dimensiones que aquel estaba alcanzando de manera progresiva, especialmente a medida que se iban poblando y urbanizando los nuevos barrios del Ensanche. Sin embargo, el pretendido progreso de dicha gobernabilidad también confrontaba con la manera en que las fuerzas de policía urbana y orden público quedaron desbordadas en sus actuaciones, extendidas con objetivos de control social novedosos, dependientes del nuevo contexto de apertura política.

A la vista de la documentación tramitada por el Ayuntamiento de Madrid puede vaticinarse la preocupación que entre las autoridades generó no solo la «trinidad impía» conformada por la mendicidad, la prostitución y los juegos prohibidos, sino también los nuevos comportamientos que afloraron con el marco de politización popular abierto en el Sexenio. Dentro de la retórica del control social y de la seguridad urbana jugó un papel importante la contención de actitudes ideologizadas que las instituciones juzgaban como contrarias a la nueva dinámica política establecida tras la caída de la monarquía borbónica. Como elementos trastornadores del orden público se definieron y fueron remitidos a la Cárcel de Villa en los primeros compases del Sexenio vecinos como José María Angulo, responsable de la rotura del escaparate de una tienda litográfica situada en la calle Mayor donde se hallaban expuestos los retratos de generales insignes de la Revolución, como Serrano y Topete ${ }^{99}$. Similar suerte corrieron Juan Tomás Pérez y Juan Fernández, por proferir palabras subversivas contra Juan Prim en la Puerta del Sol el 8 de noviembre de $1868^{100}$. Y dentro de este mismo escenario cabría situar los casos de José Mejía, detenido en la mañana del 28 de octubre de 1868 por gritar vivas a la recién destronada Isabel II en

98 AVM-S, Reclamación del alcalde del barrio de Chamberí, Simón Lerroux, sobre control del espacio urbano, seguridad y policía urbana, 8 de marzo de 1869, sig. 5-394-22. En similares términos se expresaría poco después el propio Lerroux, con motivo de las agresiones de las que fue objeto el guardia de policía urbana Juan Fernández en la plaza de Chamberí, al evitar una disputa. Véase: AVM-S, Oficios de Secretaría de la tenencia de alcaldía del distrito de Hospicio. Solicitud a la alcaldía de Madrid de más fuerza pública para el barrio de Chamberí por parte de su alcalde, 13 de diciembre de 1869, sig. 13-391-2.

${ }^{99}$ AVM-S, Juicios de policía urbana y gubernativos civiles. Tenencia de alcaldía del distrito de Centro. Denuncia por desorden público contra José María Angulo, 7 de diciembre de 1868, sig. 13-220-1.

${ }^{100}$ AVM-S, Juicios de policía urbana y gubernativos civiles. Tenencia de alcaldía del distrito de Centro. Denuncia por desorden público contra Juan Tomás Pérez y Juan Fernández, 8 de noviembre de 1868 , sig. 13-220-1. 
una taberna de la calle de Santa Brígida ${ }^{101}$, o de Guillermo Laboaga, apresado en la Puerta del Sol mientras vendía el periódico La Democracia Republicana, voceando al mismo tiempo «Abajo el Gobierno Provisional»" ${ }^{102}$.

Precisamente la tranquilidad pública y la seguridad individual contra las que atentaban esas expresiones y actitudes fueron los elementos invocados por Nicolás María Rivero en el bando publicado el 30 de enero de 1869. En él, expresaba la urgencia de acabar con los «desmanes tan favorables a la causa de la reacción» que venían produciéndose en la ciudad y de controlar el comportamiento de la población en las manifestaciones nocturnas, proclives a la reproducción de "desórdenes» y «excesos» difíciles de impedir. Las medidas que entendía como necesarias se condensaron en tres disposiciones. Con la primera se prohibían las manifestaciones populares en horario nocturno, sin que ello menoscabara «el derecho que tienen todos los ciudadanos de reunirse a cualquier hora en paraje determinado", siempre y cuando se diera previo aviso a la autoridad municipal. La segunda prohibía los gritos subversivos en el espacio público, contrarios al carácter «eminentemente pacífico» que debía existir en cualquier tipo de reunión. Y con la tercera, se responsabilizaba del cumplimiento de estas órdenes a los tenientes de alcalde de los distritos, a los alcaldes de barrio y a los guardias de policía urbana. En manos de todos ellos recaía la vigilancia de esas actitudes, si bien también se autorizaba a todos los ciudadanos a «detener y entregar a manos de la autoridad» a quienes perturbaran el orden público en las dos formas previamente citadas ${ }^{103}$.

Los alcaldes de barrio fueron figuras claves para hacer respetar en el marco socio-comunitario las normas anteriormente señaladas (principalmente las referentes a gritos subversivos contra las autoridades gubernamentales o municipales y las vinculadas a la organización de manifestaciones de obreros o de carácter asociativo a nivel laboral), pero también algunas de las disposiciones que en lo sucesivo provinieron del Gobierno Civil, en las que se especificaba la necesaria autorización que por parte de aquel debían tener todos los clubes y asociaciones políticas existentes en la ciudad ${ }^{104}$. En este último escenario, remitieron de manera sistemática comunicaciones sobre las reuniones que el republicanismo federal organizaba a nivel de barrio, bien fuera para tratar asuntos internos del partido, para discutir asuntos

101 AVM-S, Oficios de secretaría de la tenencia de alcaldía del distrito de Hospicio. Causa criminal contra José Mejía por el delito de conspiración, 28 de octubre de 1868, sig. 13-391-2.

102 AVM-S, Juicios de policía urbana y gubernativos civiles. Tenencia de alcaldía del distrito de Centro. Denuncia de gritos subversivos, 16 de febrero de 1869, sig. 13-220-2.

103 AVM-S, Bando de la alcaldía de Madrid sobre orden público, 30 de enero de 1869, sig. 4-419-14.

104 AVM-S, Circular del gobernador civil de la provincia de Madrid, Juan Moreno Benítez, sobre clubes y asociaciones políticas, 6 de octubre de 1869, sig. 4-420-80. 
municipales o para plantear criterios organizativos de cara a una cita electoral ${ }^{105}$. En algunos casos, dichas comunicaciones advertían del protagonismo y de los apoyos sociales que la citada fuerza política iba cosechando en determinadas zonas de la ciudad. Así se observaba en la información difundida a la alcaldía de Madrid por Vicente Olivares, alcalde del barrio de Puente de Toledo, situado en las afueras del suroeste. En sus informes, Olivares comentaba la fuerza organizativa que los federales de ese enclave iban asumiendo y los «planes vastísimos» que tenían preparados «para la hora de arrojarse a las luchas» contra el Gobierno. Algo que le llevó a tomar la iniciativa y proponer al consistorio la patrulla periódica y detenida de ese enclave, acompañado de Alfonso García, Benito Espinosa, Genaro García, Rafael Domínguez, Ginés Pastor, Alfonso Castellanos, Sebastián García y Ángel Escalona. Estos últimos no eran otros que los que Olivares definía como «vecinos honrados» comprometidos con el progresismo. El objetivo de todos ellos: sostener el «orden y la tranquilidad de la sociedad y del vecindario» en términos políticos ${ }^{106}$.

A este control sobre las actitudes políticas en el medio urbano habría que sumar el que se intentó aplicar en otros muchos escenarios. Por ejemplo, en la estación ferroviaria del Mediodía y en las casas de huéspedes de sus alrededores, frecuentadas por viajeros que eran víctimas de abusos, robos y estafas nada más llegar a la ciudad ${ }^{107}$. O en las cada vez más atestadas casas de dormir de los barrios del distrito de Centro, que servían de refugio a individuos tipificados como sospechosos desde un punto de vista político y social por las autoridades ${ }^{108}$. O en cafés como el de San Joaquín, donde se formaban aglomeraciones públicas en horario nocturno ${ }^{109}$; en teatros como el de las Novedades, a cuyas puertas confluían un número de revendedores de billetes cada vez más significativo ${ }^{110}$; o incluso en la celebración de

105 Los ejemplos de estas prácticas son ingentes entre 1869 y 1872 . Véanse algunos en: AVM-S, Comunicaciones del Ayuntamiento de Madrid. Tenencia de alcaldía del distrito de la Latina. Circulares sobre clubes y asociaciones políticas de 1869 y 1870, sig. 14-20-9 y 14-23-1; AVM-S, Oficios de secretaría de la tenencia de alcaldía del distrito de Hospicio, 1869, sig. 13-3912 y AVM-S, Documentación de policía urbana. Tenencia de alcaldía del distrito de Hospicio, 1872, sig. 13-392-3.

106 AVM-S, Comunicaciones del Ayuntamiento de Madrid. Tenencia de alcaldía del distrito de la Latina, Circular sobre clubes políticos del alcalde de barrio de Puente de Toledo, 7 de octubre de 1869, sig. 14-20-9.

107 AVM-S, Informe sobre robos y abusos a forasteros en casas de huéspedes próximas a la estación del Mediodía, sig. 5-394-56.

108 AVM-S, Documentación de policía urbana. Tenencia de alcaldía del distrito de Centro. Circular del gobernador civil de la provincia de Madrid sobre casas de dormir e informes de las alcaldías de barrio, 24 de marzo de 1870, sig. 13-221.

109 AVM-S, Sobre aglomeración de gentes por las noches en el café de San Joaquín, 1868, sig. 5-346-70.

${ }_{110}$ AVM-S, Sobre reventa ilegal de billetes en el teatro de las Novedades, diciembre de 
fiestas populares en las que las autoridades vaticinaban posibles contravenciones de los valores cívicos y morales que buscaban implementar y de los dispositivos institucionales que planteaban frente a la apropiación individual o colectiva del espacio público. Así, por ejemplo, el Carnaval, en la medida en que se asociaba a conductas excesivamente licenciosas e incluso transgresoras de unos patrones hegemónicos de moderación y sobriedad (Presdee, 2000, pp. 38-39 y Georgiou, 2015), jugaba un papel relevante en el anterior apartado y en lo que Spencer define como el «refinamiento de la sociedad urbana» (Spencer, 1995, pp. 469-472) ${ }^{111}$. Todo ello con vistas a reordenar y disciplinar los comportamientos sociales en un pretendido espacio urbano cívico.

\section{CONCLUSIONES}

La experiencia democratizadora del poder municipal en el Madrid del Sexenio Revolucionario no solo se tradujo en la aparición de iniciativas que concernieron a nuevos proyectos urbanísticos a implementar de cara a lograr la transformación social y económica de la ciudad, principalmente representados en los trabajos de Ángel Fernández de los Ríos. Al Futuro Madrid que idearía el entonces concejal del Ayuntamiento, utópico en su realización, se sumaba otro, igualmente utópico, pero no tan conocido, para el que fundamentalmente se enfatizaba la urgencia de desarrollar unos mecanismos de buen gobierno acompasados con el cambio de escala que había verificado la ciudad con anterioridad y con las necesidades que progresivamente se habían ido imponiendo en su tejido. En líneas generales, todas esas necesidades respondían a las percepciones que sobre las características del espacio público provenían de las altas instancias locales, ejecutadas después por las autoridades subordinadas a su mando.

Así, la política municipal del Sexenio Democrático estuvo guiada por la intencionalidad de proyectar una ciudad menos opaca y más transparente que la del período monárquico, principalmente en dos vertientes compenetradas. Por una parte, en unas reglas de policía urbana que trataron de redefinirse o actualizarse en aras de crear nuevas gramáticas sobre el espacio vivido y transitado, en función de lo que las autoridades entendían como válido, provechoso y aceptable para una urbe moderna. Esas nuevas gramáticas debían plasmarse en términos de ornato, limpieza y seguridad, lo que pasaba por regular tanto ciertas pautas no tolerables de comportamiento cotidiano de los ciudadanos, como los marcos de seguridad en que se desarrollaban algunas de las principales actividades de la ciudad ligadas

1869, sig. 5-332-16.

${ }^{111}$ AVM-S, Disposiciones de vigilancia y control del orden público de la alcaldía de Madrid en Carnaval, 1869, sig. 4-406-5. 
al consumo y a la distribución, en sus esquemas formales e informales. Por otra parte, el poder local delimitó unas praxis de actuación sobre todo aquello que no resultaba lícito en los usos sociales del espacio, afectando a los colectivos que lo contravenían en términos de circulación o que resultaban amenazantes para el orden público. Mendicidad, prostitución, delincuencia asociada a juegos prohibidos e incluso actividad política desmarcada de la norma oficial asumieron un papel determinante en las políticas definidas en este último escenario.

\section{REFERENCIAS BIBLIOGRÁFICAS}

Acerbi, P. (2017). Street Occupations. Urban vending in Rio de Janeiro, 1850-1925. Austin: University of Texas Press.

Aguilera, M. (2017). Les alcaldes de barrio de Madrid (1834-1840): une police urbaine de voisinage entre ancien et nouveau régime. Nuevo Mundo, Mundos Nuevos, Debates [en línea]. https://doi.org/10.4000/nuevomundo.70591.

Alcaide, R. (1999). La introducción y el desarrollo del higienismo en España durante el siglo XIX. Precursores, continuadores y marco legal de un proyecto científico y social, Scripta Nova, 50.

Andersson, P. K. (2014). Street Life in Late Victorian London. The constable and the crowd. Basingstoke: Palgrave MacMillan.

Anguita, R. (1992). Las ordenanzas municipales como instrumento de control de la transformación urbana en la ciudad del siglo XIX. Cuadernos de Arte de la Universidad de Granada, 23, pp. 463-482.

Arias, E. (2009). Ideología y política en Sevilla bajo la monarquía de Amadeo de Saboya, Sevilla: Diputación de Sevilla.

Arias, E. (2009). La Primera República en Sevilla. Sevilla: Universidad de Sevilla.

Arias, E. (2010). La Revolución de 1868 en Sevilla. Sevilla: Ayuntamiento de Sevilla, 2010.

Atkins, P. J., Lummel, P. y Oddy, D. J. (2007). Food and the city in Europe since 1800. Aldershot and Burlington: Ashgate.

Ayuntamiento de Madrid (1841). Reglamento de Policía Urbana para la muy honorable Villa de Madrid. Madrid: s. e. 
Ayuntamiento de Madrid (1847). Ordenanzas de policía urbana y rural para la Villa de Madrid y su término. Madrid: s. e.

Ayuntamiento de Madrid (1917). Reglamentos Municipales, 1866-1917. Madrid: Imprenta Municipal.

Bahamonde, Á. (1976). Contribución al estudio del fraude en un distrito urbano: las elecciones de 1869 en Madrid. Hispania, 134, pp. 639-662.

Bahamonde, Á. y Toro, J. (1978a). Burguesía, especulación y cuestión social en el Madrid del siglo XIX. Madrid: Siglo XXI.

Bahamonde, Á. y Toro, J. (1978b). Mendicidad y paro en el Madrid de la Restauración. Estudios de Historia Social, 7, pp. 353-384.

Bahamonde, Á. (1980). El mercado de mano de obra madrileño (1850-1874). Estudios de Historia Social, 15, pp. 143-175.

Bailey, P. (1978). Leisure and Class in Victorian England: Rational Recreation and the Contest for Control, 1830-1885. New York: Methuen, 1978.

Barrie, D. G. (2010). Police in civil society: police, Enlightenment and civic virtue in urban Scotland, c. 1780-1833. Urban History, 37(1), pp. 45-65. https://doi. org/10.1017/\$0963926810000064.

Barrie, D. G. y Bromhall, S. (2016). Police courts in Nineteenth-Century Scotland. Volume 2. Boundaries, behaviours and bodies. New York: Routledge. https:// doi.org/10.4324/9781315601038.

Bluestone, D. M. (1991). The Pushcart evil. Peddlers, merchants and New York City's streets, 1890-1940. Journal of Urban History, 18(1), pp. 68-92. https://doi. org/10.1177/009614429101800104.

Bonet, A. (1975): Ángel Fernández de los Ríos y la génesis del urbanismo contemporáneo. Introducción a la edición facsímil de: Á. Fernández de los Ríos (1975 [1868]). El futuro Madrid. Barcelona, J,osé Batlló.

Burnett, J. y Oddy, D. J. (eds.). (1994). The origins and development of food policies in Europe. London: Leicester University Press. 
Calaresu, M. y Van den Heuvel, D. (2016). Food Hawkers. Selling in the streets from antiquity to the present. New York: Routledge. https://doi. org/10.4324/9781315582665.

Campos, R. (2001). Tabernas, sociabilidad obrera y control social en el Madrid de la Restauración. En P. Fraile (ed.), Modelar para gobernar. El control de la población y el territorio en Europa y Canadá. Una perspectiva histórica (pp. 4356). Barcelona, Universitat de Barcelona.

Cañellas, C. (1993). El poder municipal a Barcelona de 1868 a 1875. L'Avenç, 168, pp. 18-23.

Carballo, B. (2015). El Ensanche Este. Salamanca-Retiro, 1860-1931. El Madrid burgués. Madrid: Catarata.

Chatelain, A. (1971). Pour une histoire du petit commerce de détail en France. Lutte entre colporteurs et boutiquiers en France pendant la première moitié du XIXe siècle. Revue d'histoire économique et sociale, 49(3), pp. 359-384.

Clapson, M. (1992). A bit of a flutter. Popular gambling and English society, c. 18231961. Manchester: Manchester University Press.

De la Fuente, G. (2000). Los revolucionarios de 1868. Élites y poder en la España Liberal. Madrid: Marcial Pons.

De Miguel, S. (2017a). De súbditos a ciudadanos. La emergencia de nuevas prácticas electorales en el Madrid de 1868. El Futuro del Pasado: revista electrónica de historia, 8, pp. 399-443. https://doi.org/10.14516/fdp.2017.008.001.014.

De Miguel, S. (2017b). Republicanos y socialistas. El nacimiento de la acción política municipal en Madrid (1891-1909), Madrid: Catarata.

De Miguel, S. (2017c). La fiscalización socialista de la situación benéfico-asistencial en Madrid a principios del siglo XX: El caso de los asilos nocturnos de mendicidad. Historia Social, 88, pp. 3-23.

Emsley, J., Johnson, E. y Spierenburg, P. (eds.) (2014). Social Control in Europe. Volume 2, 1800-2000. Ohio: The Ohio University Press.

Emsley, C. (1983). Policing and its context, 1750-1870. Oxford: MacMillan Press. https://doi.org/10.1007/978-1-349-17043-2. 
Espadas, M. (1981). Madrid, de la Revolución a la Restauración (1868-1874). Madrid: Artes Gráficas Municipales.

Ezquiaga, J. (1990). Normativa y forma de ciudad. La regulación de los tipos edificatorios en las ordenanzas de Madrid. Madrid: UPM, Tesis Doctoral.

Fernández García, A. (2003). El estreno del sufragio universal en Madrid (1869). Cuadernos de Historia Contemporánea, n. extra, 71-83.

Flaquer, R. (1977). La clase obrera madrileña y la primera internacional (18681874). Madrid: Cuadernos para el Diálogo.

Fraile, P. (2001). Modelar para gobernar. El control de la población y el territorio en Europa y Canadá. Una perspectiva histórica. Barcelona: Universidad de Barcelona.

Fraser, D. (1976). Urban politics in Victorian England. The structure of politics in Victorian Cities. Leicester: Leicester University Press. https://doi. org/10.1007/978-1-349-05137-3.

Georgiou, D. (2015). Redefining the Carnivalesque: The construction of Ritual, Revelry and Spectacle in British Leisure Practices through the idea and model of Carnival, 1870-1939. Sport in History, 35, pp. 335-363. https://doi.org/10.10 80/17460263.2015.1088462.

Geyzen, A. (2012). Marchands ambulants, réglementation et police à Bruxelles au XIXe siècle. Le Mouvement Social, 238(1), pp. 53-64. https://doi.org/10.3917/ Ims.238.0053.

Giménez Muñoz, Mạ C. (2006). El Asilo de Mendicidad de San Fernando, 1846-1900. Sevilla: Universidad de Sevilla.

González Lorente, E. (2008). Libertad o religión. Pamplona en el Sexenio Democrático (1868-1876). Pamplona: Universidad Pública de Navarra.

Green, D. R. (1982). Street trading in London: a case study of casual labor, 18301860. En J. H. Johnson y C. G. Pooley (dirs.), The structure of nineteenth-century cities (pp. 129-151). London: Croom Helm.

Guereña, J. L. (2003). La prostitución en la España contemporánea. Madrid: Marcial Pons. 
Guillem-Llobat, X. y Perdiguero, E. (2014). Control de la calidad de los alimentos y Urban Penalty a propósito del caso valenciano (1881-1915). Historia Social, 80, 113-131.

Gutiérrez Lloret, R. A. (1999). Canvi polític i mobilització electoral en la revolució del 1868. Recerques: Història, economia i cultura, 39, pp. 31-54.

Hernández Adell, I. (2012). La difusión de un nuevo alimento: producción y consumo de leche en España, 1865-1936. Barcelona: UAB, Tesis Doctoral.

Higueras, E. (2016). Manuel Ruiz Zorrilla. Con los Borbones, jamás. Madrid: Marcial Pons.

Huertas, R. (2002). Vivir y morir en Madrid: la vivienda como factor determinante del estado de salud de la población madrileña (1874-1923). Asclepio, 54(2), pp. 253-276. https://doi.org/10.3989/asclepio.2002.v54.i2.150.

Inwood, S. (1990). Policing London's Morals: The Metropolitan Police and Popular Culture, 1829-1850. London Journal, 15, pp. 129-146. https://doi.org/10.1179/ Idn.1990.15.2.129.

Janué, M. (2002). Els polítics en temps de revolució. La vida política a Barcelona durant el Sexenni revolucionari. Vic, Eumo Editorial.

Kelley, V. (2019). Cheap Street. London's Street markets and the cultures of informality, c. 1850-1939. Manchester, Manchester University Press. https:// doi.org/10.7765/9781526131706.

Lawrence, P. (2004). Policing the poor in England and France, 1850-1900. J. Emsley, E. Johnson y P. Spierenburg (eds.). Social control in Europe. Volume 2: 18002000 (pp. 210-225). Ohio: The Ohio State University Press.

Lefebvre, H. (2003 [1974]). La producción del espacio. Madrid: Capitán Swing.

Llano, S. (2018). Discordant notes. Marginality and Social Disorder in Madrid, 1850-1930. Oxford: Oxford University Press. https://doi.org/10.1093/ oso/9780199392469.001.0001.

Lousada, M. A. (2005). Una nuova grammatica per lo spazio urbano: la polizia e la città a Lisbona, 1760-1833. Storia Urbana, 108, pp. 67-85. 
Martínez Lorea, I. (2013): Henri Lefebvre y los espacios de lo posible. Prólogo de: H. Lefebvre (2013 [1974]). La producción del espacio. Madrid, Capitán Swing, 2013 [1974].

Maza E. (1999). Pobreza y beneficencia en la España contemporánea, 1808-1936. Barcelona: Ariel.

Merriman, J. (2006). Police stories: Building the French State, 1815-1851. New York: Oxford University Press. https://doi.org/10.1093/acprof:0 so/9780195072532.001.0001.

Mira Abad, A. (2006). Secularización y mentalidades. El Sexenio Democrático en Alicante (1868-1875). Alicante: Universidad de Alicante.

Monkonnen, E. H. (1981). Police in Urban America, 1860-1920. Cambridge: Cambridge University Press. https://doi.org/10.1017/CBO9780511572449.

Monlleó, R. (1996). La Gloriosa en Valencia (1864-1869). Valencia: Edicions Alfons el Magnánim.

Munting, R. (1996). An economic and social history of gambling in Britain and the USA. Manchester, Manchester University Press. https://doi.org/10.1007/ s12117-997-1182-0.

Nieto Sánchez, J. A. (2004). Historia del Rastro. Los orígenes del mercado popular de Madrid, 1740-1905. Madrid: Visión Net.

Ogborn, M. (1993). Ordering the city: surveillance, public space and the reform of urban policing in England, 1835-1856. Political Geography, 12(6), pp. 505-521. https://doi.org/10.1016/0962-6298(93)90002-0.

Pallol, R. (2013). Una ciudad sin límites. Transformación urbana, cambio social y despertar político en Madrid (1860-1875). Madrid: Catarata.

Pallol, R. (2015). El Ensanche Norte. Chamberí, 1860-1931. Un Madrid Moderno. Madrid: Catarata.

Paris, Á. (2017). Alcaldes, langostas y negros en el barrio de la Comadre. Los alcaldes de barrio y la Superintendencia General de Policía en Madrid (1823-1833). Nuevo Mundo, Mundos Nuevos, Debates [en línea]. 
Pascual, S. (2002). La inviolabilidad de domicilio en la Constitución de 1869. Revista de derecho político, 55-56, pp. 453-472.

Perdiguero, E. (2001). Hacia una organización sanitaria periférica: Brigadas Sanitarias e Institutos Provinciales de Higiene. En J. Atenza y J. Martínez Pérez (eds.). El centro secundario de higiene rural de Talavera de la Reina y la sanidad española de su tiempo (pp. 43-73). Toledo: Junta de Comunidades de Castilla-La Mancha.

Pérez Roldán, C. (2001). El Partido Republicano Federal: 1868-1874. Madrid: Endymion.

Phillips, M. (1992): The evolution of markets and shops in Britain. En J. Benson y G. Shaw (eds.). The evolution of retail systems, c. 1800-1914 (pp. 53-76). Leicester: Leicester University Press.

Pino Abad, M. (2011). El delito de juegos prohibidos. Análisis histórico-jurídico. Madrid: Dykinson.

Presdee, M. (2000). Cultural Criminology and the Carnival of Crime. London: Routledge, 2000.

Requena, J. (2003). Transformaciones urbanas y policía en la Barcelona del siglo XIX. Mélanges de l'école française de Rome, 115(2), pp. 827-844. https://doi. org/10.3406/mefr.2003.10067.

Requena, J. (2013). Policía y desarrollo urbano en la ciudad contemporánea, Barcelona, Universidad de Barcelona, Tesis Doctoral.

Revest, D. (2002). Street trading versus street traffic in Victorian and Edwardian London. Cycnos, 19-1 [en línea].

Ruiz Palomeque, E. (1976). Ordenación y transformaciones urbanas del casco antiguo madrileño durante los siglos XIX y XX. Madrid: Instituto de Estudios Madrileños.

Sánchez Ceballos, A. (2015). Del Asilo de San Bernardino al Asilo-Escuela de la Paloma. El tránsito de los madrileños pobres en el siglo XIX. Majadahonda.

Sánchez Collantes, S. (2007). Demócratas de antaño. Republicanos y republicanismo en el Gijón decimonónico. Gijón: Trea. 
Sánchez de Juan, J. A. (2002). Civitas et Urbs. The idea of the City and Historical Imagination of Urban Governance in Spain, 19th and 20th centuries. Firenze: Instituto Universitario de Firenze, Tesis Doctoral.

Serrano, R. (1992). La Revolución de 1868 en Castilla y León. Valladolid: Universidad de Valladolid.

Serrano, R. (2001). La historiografía en torno al Sexenio, 1868-1874: entre el fulgor del centenario y el despliegue sobre lo local. Ayer, 44, pp. 11-32.

Serrano, R. (2002). España, 1868-1874: nuevos enfoques sobre el Sexenio Democrático. Valladolid: Consejería de Educación y Cultura.

Serrano, R. (2018). Historiografía reciente en torno a la Revolución Gloriosa y el Sexenio Democrático (1868-1874). En D. Caro (ed.), La Revolución de 1868 en Andalucía (pp. 15-44). Madrid: Peripecias.

Spencer, E. G. (1995). Regimenting Revelry: Rhenish Carnival in the Early Nineteenth Century. Central European History, 28(4), pp. 457-481. https://doi.org/10.1017/ S0008938900012279.

Storch, R. D. (1975-1976). The Policeman as Domestic Missionary: Urban Discipline and Popular Culture in Northern England, 1850-1880. Journal of Social History, 9, pp. 481-509. https://doi.org/10.1353/jsh/9.4.481.

Taylor, D. (1997). The new police in nineteenth-century England. Crime, conflict and control. Manchester: Manchester University Press.

Vega-Rey, L. (1885). Pobreza y mendicidad (estudio crítico filosófico-social). Madrid: Imprenta de Enrique Teodoro.

Vicente, F. (2015). El Ensanche Sur. Arganzuela, 1860-1931. Los barrios negros. Madrid: Catarata.

Vidal Galache, F. (1992). ¿Qué hacemos con los pobres? El origen del Asilo de San Bernardino (1834). Espacio, tiempo y forma. Serie V. Historia Contemporánea, 5, pp. 305-316. https://doi.org/10.5944/etfv.5.1992.2746.

Villena, R. (2005). El sexenio democrático en la España rural. Ciudad Real (18681874). Ciudad Real: Instituto de Estudios Manchegos. 